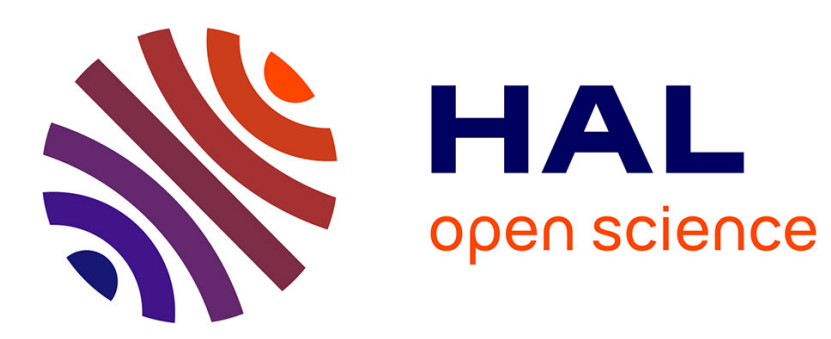

\title{
The odour of human milk: Its chemical variability and detection by newborns
}

Hélène Loos, Daniela Reger, Benoist Schaal

\section{To cite this version:}

Hélène Loos, Daniela Reger, Benoist Schaal. The odour of human milk: Its chemical variability and detection by newborns. Physiology \& behavior, 2019, 199, pp.88-99. 10.1016/j.physbeh.2018.11.008 . hal-02414388

\section{HAL Id: hal-02414388 \\ https://hal.science/hal-02414388}

Submitted on 25 May 2020

HAL is a multi-disciplinary open access archive for the deposit and dissemination of scientific research documents, whether they are published or not. The documents may come from teaching and research institutions in France or abroad, or from public or private research centers.
L'archive ouverte pluridisciplinaire HAL, est destinée au dépôt et à la diffusion de documents scientifiques de niveau recherche, publiés ou non, émanant des établissements d'enseignement et de recherche français ou étrangers, des laboratoires publics ou privés. 


\section{Accepted Manuscript}

The odour of human milk: Its chemical variability and detection by newborns

Helene M. Loos, Daniela Reger, Benoist Schaal

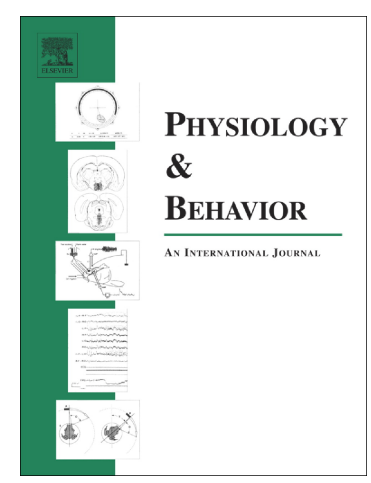

PII:

S0031-9384(18)30640-1

DOI: https://doi.org/10.1016/j.physbeh.2018.11.008

Reference:

PHB 12358

To appear in:

Physiology \& Behavior

Received date:

12 August 2018

Revised date:

29 October 2018

Accepted date:

5 November 2018

Please cite this article as: Helene M. Loos, Daniela Reger, Benoist Schaal, The odour of human milk: Its chemical variability and detection by newborns. Phb (2018), https://doi.org/10.1016/j.physbeh.2018.11.008

This is a PDF file of an unedited manuscript that has been accepted for publication. As a service to our customers we are providing this early version of the manuscript. The manuscript will undergo copyediting, typesetting, and review of the resulting proof before it is published in its final form. Please note that during the production process errors may be discovered which could affect the content, and all legal disclaimers that apply to the journal pertain. 
Physiology \& Behavior, special issue "The role of body odors and olfaction in interpersonal

relationships"

\section{The odour of human milk: its chemical variability and}

\section{detection by newborns}

Helene M. Loos ${ }^{\mathrm{a}, \mathrm{b}}$, Daniela Reger ${ }^{\mathrm{a}, \mathrm{b}}$, Benoist Schaal ${ }^{\mathrm{c}}$

${ }^{a}$ Chair of Aroma and Smell Research, Friedrich-Alexander-Universität Erlangen-Nürnberg, Henkestr.

9, 91054 Erlangen, Germany.

${ }^{\mathrm{b}}$ Sensory Analytics Department, Fraunhofer Institute for Process Engineering and Packaging IVV,

Giggenhauser Str. 35, 85354 Freising, Germany

${ }^{\mathrm{c}}$ Developmental Ethology and Cognitive Psychology Group, Center for Taste, Smell and Food Science, CNRS-Université de Bourgogne, 9E bd Jeanne d’Arc, 21000 Dijon, France

E-Mail: helene.loos@fau.de,daniela.reger@ivv.fraunhofer.de, benoist.schaal@u-bourgogne.fr

Corresponding author: Helene Loos, e-mail: helene.loos@fau.de 


\section{Abstract}

Human milk odour has for long elicited research interest with regard to its function in breastfeeding initiation. The present review aims to provide an overview of the behavioural effects of human milk odour in the human neonate, considering different types of response measures in a feeding or nonfeeding context. Further, an overview of the current knowledge of odorant composition and factors influencing milk odour is provided by summarizing results from analytical studies using olfactometry, and addressing changes in milk odour due to storage, lactational stage, and maternal dietary intake of odorous substances. We finally highlight some issues for future research.

\section{Keywords}

Human, Milk, Neonate, Behaviour, Gas Chromatography-Olfactometry/Mass Spectrometry, Body Odour.

Declarations of interest: none. 


\section{Introduction}

Food aroma scientists elucidate the chemical structure of food odorants, and the principles of their formation and of their release from the food matrix. They further investigate the biochemical interaction of food odorants with the organism, considering ensuing metabolic responses, and perceptual and behavioural effects. This also holds true for research on milk aroma. Human milk, however, is a special food for at least two reasons. First, its consumption is restricted to early human life and comes along with close mother-infant interaction. Second, it is of human origin. Thereby, another facet is added to research on human milk odour, namely the question of whether it conveys some conspecific information that is implicated in stimulating sucking behaviour and in favouring the development of the infant's brain and body functions.

In the following, we take an interdisciplinary perspective to human milk odour research by providing a review on the current knowledge of: i) the neonatal perception and reaction to human colostrum and milk odour, and ii) the chemical nature of the odorous compounds of human colostrum and milk (hereinafter: colostrum and milk). We aim to identify the principal findings in the respective fields of ethology, developmental psychobiology and food chemistry, and fruitful questions for future research both within each field and at their interface. We specifically aim to stimulate research into the chemosensory and chemical principles underlying the behavioural and physiological functions of milk odour.

\section{Human neonates' responses to human milk odour}

Colostrum is the breast fluid obtained before the second secretory phase of lactation (stage II lactogenesis) which occurs around the third day after parturition in humans, and is thus the first mammary secretion ingested by the neonate. Considering its significance, and the significance of milk in a neonate's and nursling's life, generally being their sole nourishment, it is tempting to expect neonates to detect the odours of these breast secretions and to behaviourally respond to them positively (i.e., by appetence and acceptance). In the present review, we aim to examine the current 
knowledge on neonatal responses to the odours of colostrum and milk alone, disregarding other potential maternal and mammary sources of olfactory information (otherwise reviewed in [1-3]), unless such stimuli have been directly compared with milk.

\subsection{Head orientation and oral movements in double choice tests}

In 1975, Macfarlane [4] pioneered neonate infant responsiveness to the odour of the breast of their lactating mothers. He simultaneously presented an odorous breast pad and an odourless control pad to 2- to 7-day-old newborns, recording the duration of head orientation towards each of these stimuli. The neonates discriminated between these two stimuli by turning their head for a longer time towards the breast pad than to the control. This approach was taken on and refined by other researchers, to assess neonatal responses to various stimuli including milk. Thus, in a series of studies by Schaal and colleagues, 2-day-old infants were shown to display non-random responses towards the odours of colostrum and milk. The neonates turned their head longer to a stimulus bearing 20 drops of their mother's colostrum compared to an aqueous odourless control [5]. Similarly, 4-day-old newborns oriented longer and showed longer mouthing movements to a stimulus bearing 20 drops of their mother's milk compared to an odourless control. This was also the case when the control was replaced by a stimulus bearing 20 drops of the age-matched milk from another woman (hereinafter: unfamiliar milk; $[5,6])$. These results imply, first, that the odours of colostrum and milk are detected by 2- to 4-day-old neonates; second, that these odours elicit an orienting and mouthing response; and third, that 4-day-old infants recognize their mother's milk odour, meaning that for them, some information (odour familiarity, quality) differs between the milks from different women.

The next question to ask is how neonates behave when simultaneously exposed to two maternal stimuli collected from different body sites, e.g. to maternal odours from the prenatal environment as compared to odours from the postnatal environment. This question was addressed using 20 drops of colostrum or milk as the postnatal stimulus, and 20 drops of amniotic fluid as the prenatal stimulus. Whereas the duration of head orientation towards the one or the other stimulus was not 
discriminative in three groups of breast-fed neonates with a mean age of 10, 34, and 55 hours after birth, respectively, two other groups of neonates, tested at a mean age of 85 and 114 hours, oriented their head significantly longer to the postnatal stimulus, i.e., the milk stimulus [7]. This result of agerelated responsiveness towards simultaneously presented prenatal and postnatal odour cues of their own mothers was replicated with two other groups of neonates (mean age: 42 and 91 hours, respectively; [5]). However, such a shift in behavioural response did not occur in bottle-fed infants who oriented longer towards the amniotic fluid stimulus on day 4 when it was paired with their formula ([8]; see also [9]).

Human infants' responses have also been tested when simultaneously exposed to two odours experienced postnatally in the context of breastfeeding. When their mother's milk and neck odour, or their mother's milk and areola odour were paired, 3-day-old newborns did not show any preferential orientation or discriminative mouthing response [10]. However, when milk odour was opposed to breast odour, 3-day-old neonates tended to orient their head more often, yet no longer, to the breast odour [10].

Taken together, these results suggest, first, that the odour of mammary secretions gains attractiveness over the odour of amniotic fluid during the first few postnatal days (see [7] for a discussion of possible underlying mechanisms), and, second, that, in 3-day-old neonates, the odour of milk elicits orienting and mouthing responses that are equivalent to those elicited by maternal neck or breast odours.

It remains to ask about the relative attractiveness of milk odour with regard to non-maternal odours, including the odours of animal milk and animal milk-based formulas. Marlier and Schaal [11] presented 3- to 4-day-old infants with milk of an unfamiliar mother and unfamiliar bovine milk-based formula (i.e., formula that had not been ingested by the infants before). Irrespective of the feeding mode (bottle or breast), the newborns oriented longer and with shorter latency towards the milk odour, and showed more search-like mouthing movements to it. Similarly, 3- to 4-day-old bottle-fed neonates evinced enhanced head orientation and scanning/mouthing activation towards milk odour 
from an unfamiliar mother as compared to the iso-intense odour of the formula milk they had been fed since birth [11]. Otherwise, studying 3- to 4-day-old neonates' behaviour in a test opposing milk odour and a chamomile scent (conveyed by a cream applied on the areola), Delaunay-El Allam et al. [12] showed that breast-fed infants turned their head longer and expressed longer mouthing movements towards their mother's milk odour than to the chamomile odour. However, when the test was performed with a group of infants having been exposed to the chamomile scent during breastfeeding in the days before, no such discriminative response was observed [12]. One can thus conclude, first, that 3- to 4-day-old neonates preferentially orient towards human milk odour when it is paired with a non-maternal odour, and, second, that associative learning during breastfeeding renders the learned odour as attractive as the odour of milk.

In sum, two-choice tests including human milk odour as a stimulus have shown that the odour of colostrum elicits neonatal orienting and mouthing response as early as on day two (earlier behaviour has not been investigated, to date). The relative salience of prenatal and postnatal odour cues changes with the newborn's age and with the lactational stage of milk secretion, the odour of transitional milk (milk secreted in the several day-long transition between colostrum and mature milk) becoming more attractive to 3- to 4-day-old breast-fed neonates than the odour of amniotic fluid. In contrast to this, different postnatal maternal odours (milk, breast, and neck odours) appear to be barely behaviourally discriminated at this age (but more tests are needed). Finally, both bottleand breast-fed 3- to 4-day-old neonates orient longer and show more mouthing to the odour of milk as compared to formula odour, and analogous results were obtained with low-intensity artificial odour mixtures associated with breastfeeding. Despite this evidence, however, our understanding of the relative attractiveness of milk odour compared to other postnatal odours associated with the mother, and similarly to non-conspecific odours, appears still incomplete.

\section{$\underline{2.2 \text { (Non)-nutritive sucking in a feeding context }}$}


The effect of milk odour on sucking or searching behaviour in a feeding context has been investigated in infants born at term and in infants born preterm. Thus, when 24-day-old preterm infants (mean gestational age (GA): 30.3 weeks) were orthonasally stimulated with the odour of fortified breast milk (thawed breast milk charged with a fortifier powder containing similar constituents as bovinemilk based formula) during nasal tube feeding of this milk, non-nutritive sucking on the odourreleasing pacifier was enhanced compared to a control condition. Such an effect was not observed in a group stimulated with formula (mean GA: 29.3 weeks; [13]). The study, however, lacks information on certain experimental parameters (e.g., familiarity of formula odour, origin and storage duration of human milk). In another study on 2- to 5-week-old preterms (mean GA of the two groups: 31.8 and 31.2 weeks), Raimbault et al. [14] investigated how exposure to their mother's milk odour just before the initial breastfeeding trials influences the neonates' breastfeeding behaviour. Compared to the control group, the regularly exposed infants evinced longer maximal durations of sucking bouts and more frequent long sucking bouts (i.e., bouts composed of 7 or more sucking movements), and ingested more milk at a later breastfeeding session. Nutritive sucking parameters were further monitored in a bottle-feeding session with 12-day-old term infants who had been separated from their mothers since birth [15]. The newborns evinced a higher expression pressure and sucking frequency when their mother's milk odour was presented orthonasally, as compared to the formula odour condition and the water control condition. Other researchers compared the sucking behaviour of term infants when being fed formula and milk without additional orthonasal odour stimulation (i.e., milk odorants were released intraorally and reached the olfactory areas retronasally). Whereas no or only marginal differences were reported concerning the neonates' sucking behaviour, a consistent outcome of these studies was a higher respiration frequency when the neonates were fed milk in comparison with formula [16-18].

Finally, Doucet et al. [19] tested the behaviour of 3-day-old neonates when facing their mother's breast in a nursing position. The breast was partly or completely covered by a transparent plastic film to avoid the release of milk- or breast-related volatiles, or to selectively release odorants from the 
nipple only, from the areola only, or from milk only. Whereas the newborns' behaviour in the odorous conditions was different from their behaviour in the odourless condition for a range of parameters (e.g., crying time, duration of opening the eyes, duration of licking, sucking and rooting), the type of odorous condition ("total breast", "areola only", "nipple only", "milk only") did not have a major influence on oral activation or other behaviours, with the exception of rooting, which was enhanced in the "total breast" condition compared to the "areola only" and "milk only" conditions.

In sum, these results indicate that milk odour, but not formula odour or water, promotes (non)nutritive sucking in a feeding context. However, this conclusion appears provisional in view of the low number of studies and often the special early life circumstances of the participating newborns (preterm birth). Hence, the effect of milk odour on nutritive sucking in a feeding context, and its relative potency to stimulate sucking with regard to other maternal and non-maternal odours, still deserves further study.

\subsection{Oral movements, facial expressions, and physiological responses in sequential tests}

Sequential tests permit administering numerous odours to neonates, and in those studies assessing neonatal responses to milk odour, the stimulus set generally comprised additional maternal or dairy substrates, specific odours or odorants, and an odourless control. Studies using sequential stimulus administration are designed to judge a stimulus' relative efficacy to induce specific neonatal facial actions or physiological responses, and have been used to screen for odorants that may elicit responses comparable to those towards milk odour. In a study by Mizuno et al. [20], two groups of newborns were sequentially presented on both day 1 and day 4 postpartum with their mothers' colostrum / milk, the colostrum / milk from an unfamiliar mother, formula (origin not specified), orange juice, and water. All neonates had been separated from their mothers and bottle-fed during the first 24 hours. The neonates were divided into two groups. Whereas group A had skin-to-skin contact, including suckling, for an average of 64 minutes immediately after birth, group B did not experience skin-to-skin contact or suckling before being separated from the mothers. On day 4, 
group A, but not group B, showed more frequent mouthing to their own mother's milk odour than to the unfamiliar milk odour. In both groups, no discriminative responsiveness to the odours of their own mother's colostrum and unfamiliar colostrum was evident on day 1 . Further, on both days 1 and 4, the two groups evinced a higher mouthing frequency to the odours of familiar and unfamiliar colostrum / milk than to the odours of formula, orange juice, and water, and the mouthing frequency was higher to the odour of formula than to that of orange juice and water. These results indicate that familiar and unfamiliar human milk odour leads to a higher mouthing frequency than formula odour, a non-dairy odour (orange juice), and the odourless control stimulus as early as on day 1 . However, this has not been replicated in other studies. Thus, in a study conducted by Soussignan et al. [21], no evidence of milk-specific facial responsiveness was obtained in 3-to 4-day-old breast- and bottle-fed neonates the responses of whom were compared for unfamiliar milk odour, water, and iso-intense vanillin and butanoic acid odours. In addition to the neonates' behaviour, the authors also recorded their breathing rate and skin temperature to assess physiological responses to the odour stimuli. No discriminative responses occurred with regard to the skin temperature. The proportion of behaviourally active neonates, the duration of facial displays, the number of action units (distinct muscle movements according to the Facial Action Coding System [22]), and the increase in respiratory rate were higher for the three odorous stimuli (milk, vanillin, and butanoic acid) than for the control. Further, more neonates showed disgust expressions (facial action units 9 and 10 ) when smelling butanoic acid odour than water. In the same study, breast-fed neonates evinced a higher breathing rate change to unfamiliar milk than to unfamiliar formula, and vice versa in bottle-fed neonates. Thus, even if Soussignan et al. [21] found distinct facial and respiratory responses to milk odour and to the odourless control, indicating perception of milk odour by the neonates, the respiratory responses to milk and formula appeared to be modulated by the feeding mode of the infants, and the responses towards milk odour did not significantly differ from those towards the odours of iso-intense vanillin and butanoic acid. One might speculate that this result is related to the iso-intensity of the stimuli (cf. [23]), or to the presence of these two odorants in milk (cf. [12]). Yet, the inconsistencies in the relative efficacy of milk, formula, other odorants, and the odourless control 
to induce sucking or other facial expressions may also be due to different methods applied in the different studies, e.g., regarding the neonate's behavioural state or the duration of stimulus presentation. For instance, Mizuno et al. [20] recorded the mouthing frequency during a 120 s-long odour stimulation, whereas Soussignan et al. [21] administered the odour stimuli for $10 \mathrm{~s}$ each.

Recording oro-cephalic responses, respiratory parameters and heart rate during sequential stimulus administration, Doucet et al. [24] investigated responses of 3-day-old infants to the odours of their familiar food (milk or formula), unfamiliar formula, non-pasteurized cow milk, vanillin, and water. Further, the stimulus set comprised unfamiliar milk, sebum, and areolar gland (AG) secretions. Amongst others, they observed that the odour of unfamiliar AG secretions activated oro-cephalic actions during the 10-s-stimulus presentation to a higher extent than the odours of unfamiliar milk and of familiar food. Analogous results were obtained for the maximum change of inspiratory rate upon stimulus administration. Further, in the 10-s-period after stimulus presentation, nonpasteurized cow milk odour led to a higher oro-cephalic activation than the odour of unfamiliar human milk. Whereas no significant stimulus-specific alteration of respiratory rate became evident, bottle-fed but not breast-fed neonates evinced a higher increase in heart rate to the odour of AG secretions than to unfamiliar milk and to their familiar food. These results point towards a high efficacy of AG secretions in inducing neonatal physiological and behavioural activation. Yet, neonates apparently did not behaviourally discriminate between milk odour and the odours of other maternal stimuli, formula, vanillin, and the control.

In a more recent work, 3-day-old neonates were studied by Loos et al. $[25,26]$ with regard to their responses to aqueous solutions of steroids, acids, and thiols occurring in milk and/or sweat. In these studies, the neonates did not enhance oral movements to their familiar feed (milk or bovine milkbased formula) as compared to the odourless control water, and the respiratory rate of the neonates did not differ between any of the stimuli. Certain of the odorous stimuli led to facial responses that differed from those elicited by the familiar feed of the newborns, but these responses appeared concentration-dependent. For example, the compound 3-hydroxy-3-methylhexanoic acid, a 
contributor to sweat odour supposed to occur in milk, elicited a longer duration of negative oro-facial responses than familiar food when it was presented at $50 \mathrm{ng} / \mathrm{L}$, but not at $0.5 \mathrm{ng} / \mathrm{L}$ or at $200 \mu \mathrm{g} / \mathrm{L}$. Such concentration-dependent effects may relate to different perceived odour intensities, familiarities, and qualities $[27,28]$, reflecting that concentration is put forward to contribute to odour identity $[29,30]$. Such concentration-dependent responsiveness to odorants is also evident in other species, on a behavioural or neuronal level [31, 32].

Using near-infrared spectroscopy (NIRS), Bartocci et al. [33] studied processing of odours by the neonatal brain. Whereas newborns younger than $24 \mathrm{~h}$ showed a higher change in oxygenated haemoglobin when presented with their own mother's colostrum odour compared to the control, this was not the case for infants older than $24 \mathrm{~h}$. No such age-dependent responsiveness was observed for vanillin which elicited a cortical metabolic activation in all infants at any age. In a more recent NIRS study, Aoyama et al. [34] found that the change in oxygenated haemoglobin was higher upon stimulation with familiar milk odour than with formula in a sample of about 5-day-old newborns, irrespective of the feeding mode.

In sum, no consistent picture is emerging from the currently available tests using milk odour in a sequential stimulus design. Discriminative responses to milk odour and the odourless control, or to milk and formula odours were only reported in part of the studies. With regard to other odorant mixtures or odorants, neonatal responses appear to depend on the nature of the stimulus, and its concentration.

The available evidence further indicates that the own mother's milk odour is recognized on day 4, and that this response is dependent on the neonates' postpartum experience of maternal odours [20]. Yet, this was not replicated by Doucet et al. [24]. Maternal stimuli other than milk applied in sequential tests were amniotic fluid (yet, no statistical comparison to responses to milk odour was performed; [21]), unfamiliar sebum and AG secretions [24], and familiar sweat [26]. From these, the odour of unfamiliar AG secretions was found to elicit a distinct neonatal response, i.e. longer orocephalic movements, as compared to the odours of unfamiliar milk and the familiar feed of the 
neonates.

Sequential tests are promising since they allow multiple comparisons between stimuli of different origins. Yet, it appears that the methodological standard for testing newborns should be implemented in future studies.

\section{$\underline{\text { 2.4 Facial expressions, motor activation, crying, and physiological responses in a pain context }}$}

Heel pricks and venipuncture are used as a routine procedure to obtain neonatal blood samples for medical tests, and it has been investigated whether related pain responses can be diminished by olfactory cues. Indeed, de Chanville et al. [35] report lower pain scores and shorter crying duration in a sample of preterm infants (median GA: 32.4 and 33.6 weeks) undergoing venipuncture while being exposed to their familiar milk odour as compared to an odourless condition. Similarly, Nishitani and colleagues [36] compared the soothing effects on 5 day-old newborns of the odours of either their own mother's milk, the milk of an unfamiliar mother, formula, and saline, in a sample of term-born newborns undergoing a heel prick procedure. The own mother's milk odour reduced significantly general motor activity, and crying and grimacing time, as compared to the other conditions. In a second experiment, the same authors further showed that the salivary cortisol concentration was increased in infants of the control group (saline) but not in the group exposed to their mother's milk odour. Analogous results were obtained by Badiee et al. [37] for the effect of familiar milk odour and formula in two groups of preterm newborns (mean GA: 43.1 and 43.5 weeks).

However, it has also been demonstrated that a familiar non-maternal odour can alleviate pain responses during venipuncture and support recovery after a heel prick procedure in preterm newborns [38]. Hence, subsequent studies aimed at comparing the soothing effect of milk and other familiar odours. In 2005, Rattaz et al. [39] investigated the behaviour of 4 groups of 3-day-old fullterm neonates during a heel prick procedure, smelling the own mother's milk, a familiar vanilla odour, an unfamiliar vanilla odour, and a dry control, respectively. Comparing the effects of familiar 
vanilla odour to those of milk odour, the infants showed equivalent crying and facial activity. Yet, during the heel prick procedure, infants smelling the milk odour moved their head to a lower extent than those smelling the familiar vanilla odour, indicating a different behaviour with maternal vs nonmaternal odours (or with less vs. more intense odours). Neshat et al. [40] reported for a venipuncture intervention that 10-day-old preterm infants in the breastmilk condition showed a lower increase in heart rate and lower decrease in blood oxygen saturation than infants presented with a familiar vanilla odour or no odour (mean GA: 31.6, 30.9, and 31.5 weeks, respectively). In the same study, pain responses in the milk group were significantly reduced compared to the two other groups both during and after venipuncture. In comparison to the control group, the pain response in the vanilla group was reduced during, but not after the procedure. Finally, Mellier and colleagues [41] demonstrated that recovery from venipuncture was more efficient in breast-fed term neonates smelling their mother's milk than in bottle-fed neonates smelling their formula and a control group smelling saline.

Taken together, these studies suggest that familiar human milk odour is more efficient in alleviating neonatal pain responses than unfamiliar human milk, formula, and familiar odorants. Nonetheless, as compared to the odourless condition, familiar odours have also been shown to reduce neonatal pain responses. Thus, it remains to ascertain whether human milk carries some components that affect inborn mechanisms of stress and pain buffering in neonates, e.g., related to the endogenous opioid system, or if the familiarity of its chemical signature is sufficient to elicit the same effects, or finally whether both processes are involved sequentially or simultaneously.

\section{$\underline{2.5 \text { Conclusions }}$}

From the above cited research, we can deduce that neonates detect the odour of human milk and show calming, orienting, and appetitive behaviour towards it. Since such behaviour results in breastfeeding success, growth, and positive perception of the infant's behaviour by the mother, milk 
odour is considered to indirectly promote and maintain mother-infant interaction and attachment.

Thereby, the nature of neonatal responsiveness to milk odour is expected to be context-appropriate, and in experimental research depends on the posed question, design, and setting. Double-choice tests and sequential tests mostly aim at quantifying responses related to feeding including preingestive (head orientation, non-nutritive sucking) and ingestive (nutritive sucking) behaviour. Accordingly, neonates are generally studied in the pre-prandial state in these tests. In contrast, when studying infant responsiveness in a pain context, milk odour has been demonstrated to reduce pain responses. One might speculate that not only the behavioural response in these different settings is different, but also the supposed dimension of chemosensory information underlying the respective behaviour. Whereas one may expect information about the presence of food to be a reinforcing driver of (pre)-ingestive behaviour, familiarity of an odour or information about the mother's presence might induce calming of the infant while experiencing pain. Such responses are, however, not restricted to milk odour. As indicated by the above-cited studies, neonates rapidly acquire odours related to breastfeeding or interaction with the mother. Together with other research (e.g., $[12,42-$ 45]), these studies thus demonstrate that human newborns are highly sensitive to odours and that the first postnatal days offer highly reinforcing conditions for odour learning. The learned odours are then capable of influencing the newborn's behaviour in a similar manner or even an equivalent manner as milk odour. Thus, it remains of interest to carve out the significance of milk odour in the postnatal odour landscape, and to expand our knowledge on neonatal behaviour towards non-milk odours. In doing this, future studies should exercise due diligence to multiple aspects of the experimental conditions, e.g., response measures, behavioural state and age of the infants, choice of stimuli, or blindness of experimenters regarding the stimulus presented.

In view of the behavioural responses of human neonates to milk odour, one might ask which odorants in human milk guide this behaviour. One should also assess which factors influence the quality of milk odour, since the maternal diet, lactation stage or storage conditions might impact the milk stimulus used for behavioural assays. 


\section{Human milk odour}

\subsection{Odorous volatiles of milk}

The main constituents of mature milk are water, lactose (5.2-7.0\%; [46]), triglycerides (2.5-6.4 \%; [46]), proteins (0.9-2.8\%; [46]), and oligosaccharides (average $16 \mathrm{~g} / \mathrm{L} ;$ [47]). Quantitatively minor constituents comprise minerals and vitamins (e.g., [48]), free amino acids (see $[49,50])$, extracellular microRNA (e.g., [51]), and cells and vesicles (see [52]). Excellent recent reviews are available covering the occurrence and function of milk macro- and micronutrients (e.g., proteins: [53, 54], lipids: [55, 56], carbohydrates: [57], minerals and vitamins: [58, 59]).

Knowing the secretion pathways [60]and the overall composition of milk, one can expect milk to contain diverse odorous structures, including compounds derived from oxidative and/or enzymatic degradation of lipids (e.g., fatty acids, aldehydes, ketones, lactones), amino acids (e.g., aldehydes, heterocyclic compounds), and carbohydrates (e.g., pyranones, furanones), as well as compounds originating from blood, and lipophilic environmental contaminants. Further, some odorous compounds may be synthesized and secreted by the mammary or skin glands. Indeed, various volatile compounds occur in milk, with important inter- and intra-individual qualitative and quantitative variations $[1,61-70]$. Further, amino acid conjugates known as precursors of sweat odour have been detected in milk [71], and might analogously contribute to milk odour after cleavage. The present review, however, focuses on those milk volatiles that are perceivable by an adult human nose, as determined via gas chromatography-olfactometry/mass spectrometry (GCO/MS; $[72,73])$. Extraction methods used in combination with GC-O comprise solvent extraction, and stir bar sorptive extraction from the headspace and from the milk. A compilation of odorants detected with these techniques is given in table 1.

Structurally diverse odorants contribute to milk odour, including aldehydes, ketones, terpenes, phenols, acids, heterocyclic structures, and steroids. Several of these compounds can be hypothesized to originate from known biosynthetic routes or degradation processes, such as lipid 
oxidation (e.g., (E)-4,5-epoxy-(E)-dec-2-enal, 1-octen-3-one; [74, 75]), carotenoid degradation (e.g., $\beta$-ionone; $[76,77])$, or carbohydrate or amino acid degradation (e.g., furaneol, 2-acetyl-1-pyrrolin, indole; $[78,79])$. Others, however, likely are environmental contaminants being transferred into the milk after maternal dermal, oral or inhalatory uptake (e.g., 2-bromophenol; [80, 81]). 
Table 1: Odorous compounds detected in milk (references [82-86]) and colostrum samples (reference [87]) by GC-O and GC-O/MS, with the reported odour description, retention index (RI) on capillary columns FFAP and DB-5, extraction technique, and best identification criterion. The odorants are listed in the order of their retention index, determined on capillary column FFAP. Certain odorants have been olfactorily detected but not identified by the authors, these are not listed.

\begin{tabular}{|c|c|c|c|c|c|c|}
\hline Compound & Odour description & RI FFAP & RI DB-5 & Extraction technique $^{1)}$ & Identification criterion ${ }^{2)}$ & Reference $^{3)}$ \\
\hline Methylpropanal & malty & 821 & 552 & $\mathrm{a}$ & $\mathrm{a}$ & {$[82]$} \\
\hline Diacetyl & butter-like & 981 & 596 & & a & {$[82],[87]$} \\
\hline Hexanal & grassy & 1079 & 801 & $a, b$ & a & [82], [84], [85] \\
\hline Hex-1-en-3-one & glue-like, metallic & 108 & 775 & a & a & {$[82]$} \\
\hline (Z)-Hex-3-enal & grassy, green & & 805 & $b$ & a & [84], [85] \\
\hline (Z)-4-Heptenal & fishy, fatty & 1233 & 896 & $b$ & $b$ & {$[84],[85]$} \\
\hline Octanal & soapy, citru & 1270 & 1000 & $a, b$ & a & [82], [87],[84], [85] \\
\hline Oct-1-en-3-one & mushroom-like & 1289 & 975 & $a, b$ & a & [82], [87], [84], [85], [86] \\
\hline 2-Acetyl-1-pyrroline & roasty, popcorn-like & 1339 & 925 & $b$ & $b$ & [87] \\
\hline (Z)-1,5-Octadien-3-one & geranium leaf-like, metallic & 1372 & 984 & $a, b$ & a & [82], [87],[84], [85] \\
\hline Nonanal & citrus-like, soapy & 1385 & 1103 & $a, b$ & a & {$[82],[87]$} \\
\hline
\end{tabular}




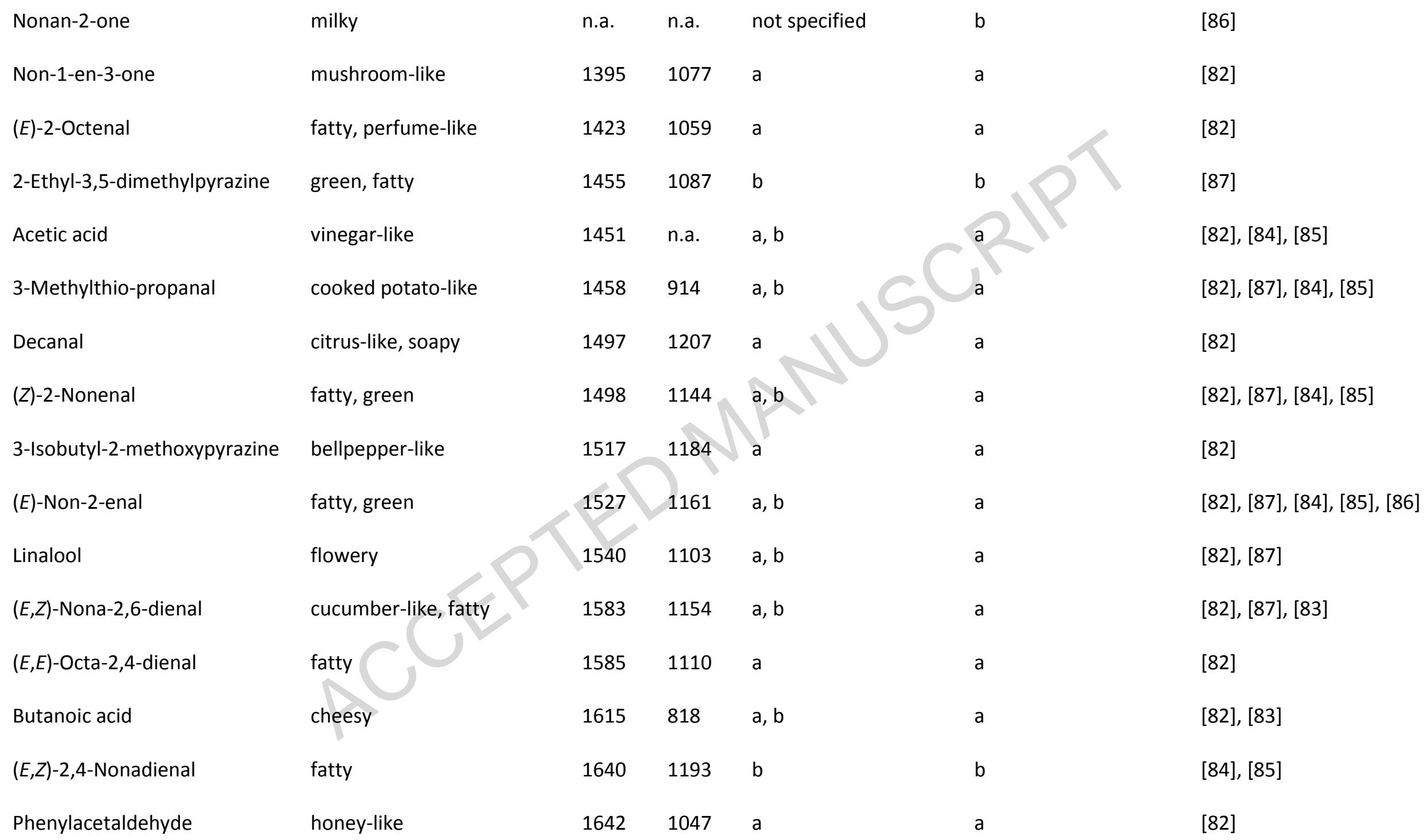


2/3-Methylbutanoic acid

(E,E)-Nona-2,4-dienal

Pentanoic acid

(E,Z)-2,4-Decadienal

$(E, E)$-2,4-Decadienal

2,4,6-Trichloroanisole

2-Methoxyphenol

2-Phenylethanol

-Octalactone

$\beta$-lonone

Maltol

Benzothiazole

2-Bromophenole

tr-4,5-Epoxy-(E)-2-decenal

-Nonalactone

Furaneol sweaty, cheesy

fatty

sweaty

fatty

fatty

cork-like, musty

smoky, ham-like

rose-like

coconut-like

violet-like

caramelized

rubber-like

plaster-like

metallic

coconut-like, flowery

caramel-like
165

1698

$1720 \quad 911 \quad a$

$1741 \quad 1291 \quad b$

$1802 \quad 1317 \quad a, b$

$1806 \quad 1331 \quad b$

$1840 \quad 1084 \quad a, b$

$19021117 \quad a, b$

$19221258 \quad b$

$19331491 \quad a, b$

n.a. n.a. not specified

$\begin{array}{lll}1961 & 1227 & b\end{array}$

$1977 \quad 1071 \quad b$

$2006 \quad 1382 \quad a, b$

$20351363 \quad a, b$

2031 a, not specified
[82], [87], [83]

[82]

[82]

[87], [84], [85]

[82], [87], [83]

[87]

[82], [87], [84], [85]

[82], [87]

[87]

[82], [87]

[86]

[82], [87], [84], [85]

[82], [87], [83]

[82], [86] 


\begin{tabular}{|c|c|c|c|c|c|c|}
\hline Octanoic acid & musty, plastic-like & 2050 & 1277 & $\mathrm{~b}$ & $a$ & {$[83]$} \\
\hline$(E, Z, Z)-2,4,7-$ Tridecatrienal & blood-like, metallic & 2115 & 1581 & $b$ & $\mathrm{~b}$ & [87], [84], [85] \\
\hline ү-Decalactone & peach-like, fruity & 2137 & 1470 & $a, b$ & a & {$[82],[84],[85]$} \\
\hline 4-Ethyloctanoic acid & goat-like & 2190 & n.a. & a & a & [82] \\
\hline$\delta$-Decalactone & coconut-like & 2190 & 1497 & $a, b$ & & {$[82],[84],[85]$} \\
\hline Sotolone & savory & 2196 & 1110 & $a, b$ & $a$ & {$[82],[84],[85]$} \\
\hline 2-Aminoacetophenone & sweet, honey-like & 2200 & 1670 & a, & $\mathrm{a}$ & {$[82],[87]$} \\
\hline Decanoic acid & fatty, rancid & 2276 & n.a. & b & a & [87], [84], [85] \\
\hline ү-Dodecalactone & peach-like, sweet & 2345 & & $b$ & $\mathrm{a}$ & [87], [84], [85] \\
\hline (Z)-6- $\gamma$-Dodecenolactone & peach-like, green & & 715 & $a, b$ & $\mathrm{a}$ & {$[82],[87],[84],[85]$} \\
\hline$\delta$-Dodecalactone & fruity, sweet & 2431 & 1701 & $a, b$ & a & {$[82],[84],[85]$} \\
\hline Indole & jasmin flower-like, faecal & 2456 & 1296 & $\mathrm{~b}$ & $\mathrm{~b}$ & [87] \\
\hline Coumarin & woodruff-like & 2465 & 1438 & $b$ & $\mathrm{~b}$ & [87] \\
\hline Dodecanoic acid & fatty, rancid & 2465 & n.a. & $b$ & a & [87], [84], [85] \\
\hline 3-Methylindole & faeces-like & 2484 & 1262 & $a, b$ & $\mathrm{a}$ & [82], [87] \\
\hline Phenylacetic acid & honey-like & 2539 & 1248 & $a, b$ & $a$ & {$[82],[84],[85]$} \\
\hline
\end{tabular}


Vanillin

3-Phenylpropanoic acid

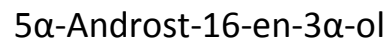

$5 \alpha$-Androst-16-en-3 $\alpha$-one vanilla-like

beewax-like, cheese-like

sandalwood-like

urine-like, animalic
2548

2600

2906

3082
1391

$a, b$

$1334 \quad b$

$2234 \quad b$

2255
[82], [84], [85]

[84], [85]

[87]

[82], [87], [84], [85], [88]

${ }^{1)}$ a: stir bar sorptive extraction and headspace-stir bar sorptive extraction, b: solvent assisted flavour evaporation

2) a: comparison of retention index, odour, and mass spectrum with reference compound, b: comparison of retention index and odour with reference compound

${ }^{3)}$ [82]: Buettner 2007, [83]: Spitzer 2013, [84]: Spitzer \& Buettner 2009, [85]: Spitzer \& Buettner 2010, [86]: Bingham et al. 2003, [87]: Loos 2015, [88]: Hartmann et al. 2013 


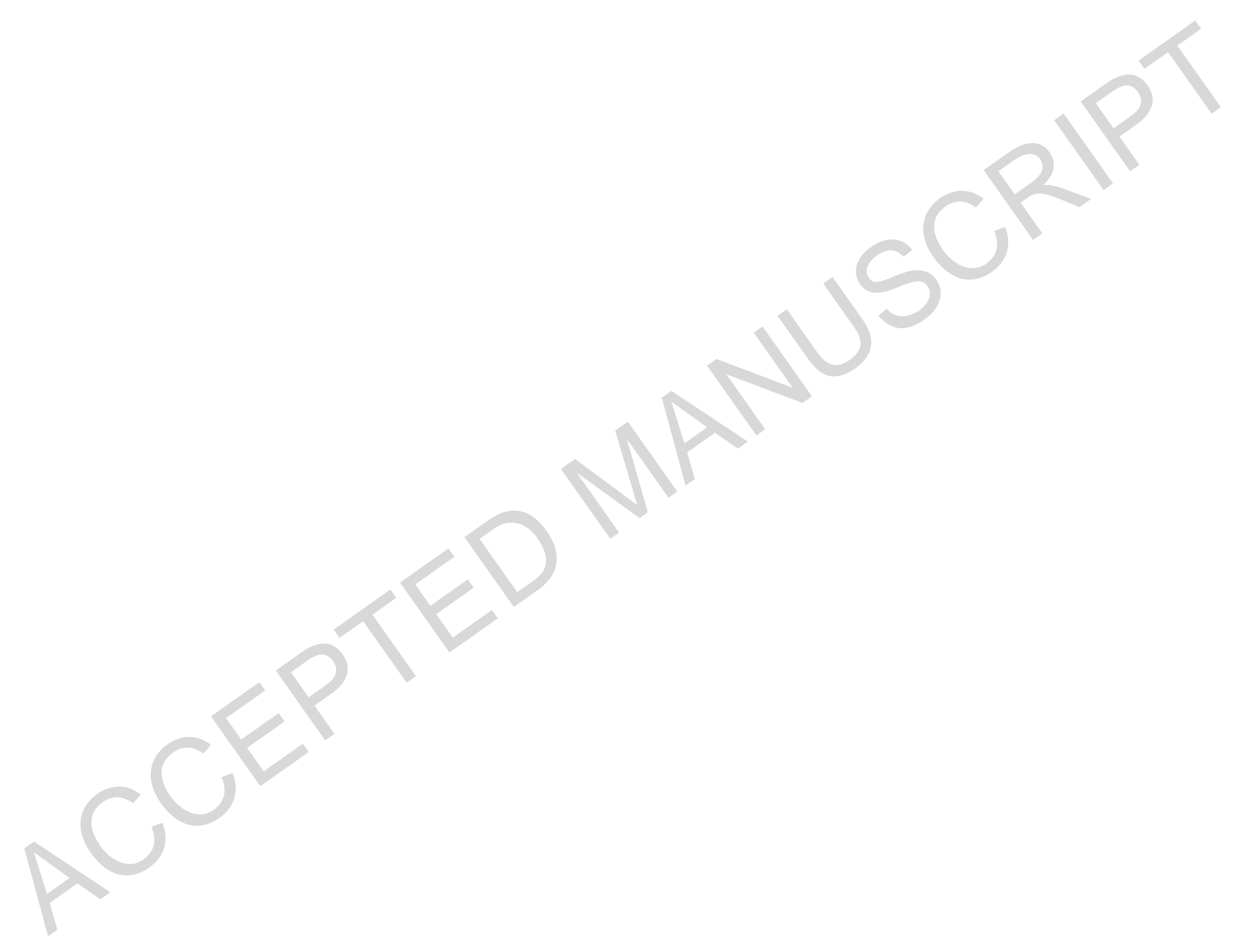


A rough estimate of the most potent odorants in an odour extract can be achieved via step-wise dilution and GC-O (aroma extract dilution analysis: AEDA; [74]). Odour sensations perceived during GC-O are generally named according to a flavour language of the respective lab, which is established in frequent trainings and panel sessions to achieve a consensus decision for the odour quality attributes of individual odorants. In 2010, Buettner and colleagues started applying AEDA to milk extracts. The fishy smelling (Z)-hept-4-enal, the metallic smelling $(E)-4,5$-epoxy-(E)-dec-2-enal, the savoury-like 3-hydroxy-4,5-dimethyl-2(5H)-furanone, the honey-like phenylacetic acid, the vanilla-like vanillin, and three musty unknown compounds had the highest flavour dilution factors and might be suggested to mainly contribute to the overall milk odour [85]. However, in another sample of milk, the compounds oct-1-en-3-one, 2/3-methylbutanoic acid, methional, vanillin, $(E)-4,5-e p o x y-(E)$-dec2-enal and dodecanoic acid had the highest flavour dilution factors [83]. Thus, the milk odour composition varies inter-individually, and this has also been noticed regarding volatile organic compounds (VOCs) in general, both on a quantitative and qualitative level $[66,86,89,90]$. Most often, however, the authors did not control for the diet of the mothers in these studies, which probably contributes to the reported variability (see below).

A more precise method to estimate the relative contribution of an odorant to the overall aroma of a food is the calculation of its "aroma value", defined as the ratio of the odorant's concentration in the food to its threshold concentration in the food matrix [91]. So far, the aroma value concept has very seldom been applied to the odour of milk. Thus, we are only aware of one study providing aroma values for 20 milk odorants, referring to thresholds determined in a model matrix containing $4 \%$ vegetable oil [92]. Amongst the selected odorants, the only compound with an aroma value $>1$ was butanoic acid. Odorants with aroma values approaching 1 (or, in some samples, exceeding 1) were oct-1-en-3-one and $(E)-4,5$-epoxy-(E)-dec-2-enal. For future determination of aroma values, the use of a more complex model matrix would be suggested to mimic the release of odorants from the milk 
matrix. Further, since the aroma value has some limitations (e.g., [93]), an odorant's impact to the overall aroma needs to be confirmed via reconstitution and omission experiments (e.g., [94]).

In sum, GC-O/MS experiments allowed to identify and quantify milk odorants which are diverse in structural and perceptual terms. In line with the overall odour of milk being of low intensity, only a few odorants have so far been determined to occur in milk in concentrations that are sufficient for orthonasal detection by adults. To fully characterize the odorant composition of milk, certain odorants still remain to be identified, and others to be quantified and evaluated in terms of their odour activity values. Thereby, the impact of the macronutrient composition of milk on the quantitative occurrence of aroma compounds and their release from the matrix should be taken into account. Available studies often lack information about experimental details which may influence the outcome of the analyses, e.g., the sampling method and time, timing of milk collection along lactation, or the diet of the mother. This information should be systematically reported in future studies.

Still, newborns might perceive milk odour in a different way than adults do. For instance, there is evidence on different olfactory sensitivity of neonates to certain odorants as compared to adults (e.g., [26]). Determining the odorants that are most important for the neonates thus remains a scientific challenge to be solved by future research.

\subsection{Factors influencing the odour of milk}

The overall composition of milk varies during the feed [95-97] and is influenced by various other factors (reviewed by $[98,99]$ ), including maternal or infantile illness [100], maternal BMI, age, and parity [101-103], daytime [46, 104], and maternal exercise (e.g., [105-107]). Studies on parallel variation in milk odour, however, are scarce. Understanding the molecular principles of aroma variation in milk is of interest from a chemical point of view, but also relevant with regard to a 
potential modulating effect of this variation on neonatal behaviour. The evidence available so far mainly relates to odour changes due to storage, lactational stage, and maternal diet.

\subsubsection{Storage}

It is common and convenient practice to store milk before feeding infants with it, be it for milk banking or to supply the mother's own nursling when she is absent, or nurslings for whom own mother's milk is not available in sufficient amounts. To ensure the quality of stored milk in terms of nutritive value, the impact of storage and prior milk treatments has been investigated for several constituents (see $[108,109]$, for reviews). Ideally, the sensory quality of milk should not be altered by storage, enabling the suckling to experience the original milk aroma. However, storage can affect the sensory attributes of milk [110], as shown by Buettner and colleagues who determined the aroma profile and odorant composition of milk samples upon storage at different conditions. They first stored milk at $4^{\circ} \mathrm{C}$ and $-19^{\circ} \mathrm{C}$ to compare the resulting odour to the odour released by fresh milk samples, i.e., milk that has not been stored but evaluated immediately after sampling. The odour of fresh human milk is of very low intensity to an adult's nose [21] and has been described as hay-like, metallic, sweet, fatty, fishy, and cooked-milk-like (attributes determined by aroma profile analyses performed by [85, 92]) or fruity, sour, and earthy [111]. After 1 and 3 days of storage at $4^{\circ} \mathrm{C}$, the overall intensity rating of milk odour increased, and certain attributes were rated with higher intensities, including "rancid" and "sweaty" attributes [92]. Concurrent quantitative analyses of 13 targeted odorants revealed that the concentrations of $(E)$-2-nonenal, $\gamma$-nonalactone, octanoic acid, decanoic acid, and dodecanoic acid increased during storage at $4^{\circ} \mathrm{C}$, possibly generating the more pronounced rancid and sweaty odour descriptions. When stored for 3 or more months at $-19^{\circ} \mathrm{C}$, however, an intense metallic, fishy, rancid and sweaty off-odour developed in human milk samples, which was not detected with storage at $4{ }^{\circ} \mathrm{C}[85,112]$. Characterizing the odorant composition of fresh samples and samples stored at $-19^{\circ} \mathrm{C}$, Spitzer \& Buettner [85] detected several carbonyl compounds and acids with increased flavour dilution factors in the sample stored at $-19^{\circ} \mathrm{C}$, notably 1 octen-3-one, (Z)-1,5-octadien-3-one, $(E)$-4,5-epoxy-(E)-2-decenal, $(E, Z, Z)-2,4,7$-tridecatrienal, $(E, Z)$ - 
2,4-nonadienal, and (E,Z)-2,4-decadienal, as well as decanoic acid, dodecanoic acid, phenylacetic acid, and 3-phenylpropanoic acid. This observation was corroborated by quantification of 20 targeted odorants in fresh and stored samples, demonstrating a statistically significant increase in the concentrations of hexanal, octanal, 1-octen-3-one, $(E)$-2-nonenal, $(E, E)$-2,4-nonadienal, $\delta$ decalactone, $\gamma$-nonalactone, $\gamma$-dodecalactone, octanoic acid and decanoic acid during storage at $-19{ }^{\circ} \mathrm{C}[90]$. The development of the metallic, fishy off-odour was prevented by heat treatment of the milk before storage, indicating that the off-odour develops by enzymatic oxidation of (poly)unsaturated fatty acids [112]. According to Spitzer and Buettner [85], preliminary experiments did not indicate a discriminative feeding behaviour of neonates $(n=4)$ who were bottle-fed milk stored at $-19^{\circ} \mathrm{C}$ (bearing the off-odour), in comparison with fresh milk. Yet, rating of the feeding behaviour was performed by the respective mother without specifying response criteria. The authors further report that the same quantities were consumed with both milks. However, the infant age, important parameter for food acceptance in infants [113], was not provided for each participating newborn, preventing a conclusion from the reported observation. In a similar study on preterm infants, Hung et al. [114] assessed heart rate, oxygen saturation, and feeding behaviour when feeding thawed milk (stored at $-13^{\circ} \mathrm{C}$ for a minimum of 6 and a maximum of 98 days) and "fresh" milk (stored at $4-7^{\circ} \mathrm{C}$ for less than 24 hours) to preterm infants (GA: $<37$ weeks, mean postmenstrual age (PA): 36.9 weeks). On a whole group level, the physiological measures did not differ between the two milks. However, in the subgroup with PA > 36 weeks $(n=10)$, thawed milk elicited more heart rate changes ( $>2$ standard deviations from the baseline) than the "fresh" milk. According to items of a Preterm Feeding Cues Coding System (PFCCS; Lin 2005, personal communication in [114]), more stress cues (e.g., crying) were observed during feeding of the milk stored at $-13^{\circ} \mathrm{C}$. This difference was significant on a whole group level and in the group with PA > 36 weeks, but not in the subgroup with PA $<36$ weeks $(n=8)$. The feeding time and efficacy, and self-regulation cues (according to PFCCS) did not differ between the two milks. Again, certain methodological information is missing, e.g., the age of the infants at testing, and the coder was not blind to the nature of the stimulus. 
In another study, Buettner and colleagues [89] investigated whether storage for 24 months at $-80^{\circ} \mathrm{C}$ would affect the overall odour or odorant composition of human milk. The aroma profile was established using the attributes fatty, metallic, grassy-green, rancid, sweaty, butter-like, sweet, haylike, egg-white-like, and fishy, which were all rated with low intensities both in the fresh and the stored milk samples. In contrast to the samples stored at $-19^{\circ} \mathrm{C}$ (see above), no significant increase in the fishy, metallic, sweaty or rancid attributes was noticed. However, the stored sample was rated as slightly sweeter compared to the fresh sample. Yet, "sweet" is an imprecise attribute. The concentrations of selected odorants did barely differ between fresh and stored samples, with the exception of $(E, E)$-2,4-decadienal, $\gamma$-dodecalactone, and $\delta$-decalactone, being a factor 1.5, 2.1, and 2.3 , respectively, higher in the stored samples [89].

In sum, different storage conditions affect the odour of milk in a different manner. Whereas short storage at $4^{\circ} \mathrm{C}$ and long storage at $-80^{\circ} \mathrm{C}$ had no or only minor influence on the aroma profile of milk, storage at $-19^{\circ} \mathrm{C}$ for more than 2 months led to an intense metallic, fishy off-odour, resulting from an increase of carbonyl compounds and acids due to lipid oxidation, and reflecting the high content of (poly)unsaturated fatty acids in milk. Newborns might thus be exposed to this off-odour when fed with milk stored at $-19^{\circ} \mathrm{C}$ for more than 2 months. Preliminary feeding experiments point towards the possibility of discriminative neonatal behaviour, but need corroboration due to methodological limitations and patchy reporting. Indeed, the field still lacks a thorough investigation of neonatal responses to the sensory properties of stored milk.

\subsubsection{Lactational stage}

The initiation of lactation is a two-stage process. The morphological and intracellular changes in the mammary gland that occur during pregnancy are referred to as lactogenesis I [60]. Lactogenesis II occurs after childbirth and is mirrored by a continuous increase in milk volume and a continuous change in milk composition during the first days postpartum [115]. Accordingly, breast secretions can be classified as colostrum (before lactogenesis II), transitory milk, and mature milk. It can be 
hypothesised that lactational stage might influence odorant composition, due to different secretory activity or closure of the paracellular pathway. Whereas we are not aware of any study addressing odour changes upon weaning, a few studies are available investigating whether the odour of milk changes during initiation of lactation.

Colostrum has been subjected to GC-MS analyses, demonstrating the presence of odorants that had been reported in milk before, including fatty acids, aldehydes, lactones, alcohols, amines, terpenes, and oxygen-containing heterocycles $[1,67,116]$. By directly comparing colostrum and mature milk samples, higher methylamine concentrations were detected in colostrum [63]. Similarly, Hartmann et al. [71] detected amino acid conjugates of human sweat odorants in colostrum and milk samples, with higher concentrations in colostrum. Yet, these analyses did not include olfactometry, and the relative impact of the detected odorous compounds on the overall odour of colostrum remains to be elucidated. Hence, we recently applied GC-O to dichloromethane distillates of colostrum and transitional milk samples obtained $<50 \mathrm{~h}$ and $>65 \mathrm{~h}$ postpartum, respectively, identifying the odorants via odour quality and retention indices on two GC capillaries of different polarity [87]. The detected odorants are listed in Table 1, and it becomes evident that many odorants of the colostrum samples also occur in mature milk samples. Yet, this still needs to be confirmed for those odorants that had not been described in mature milk before. These were the roasty smelling 2-acetyl-1pyrroline, the green, earthy smelling 2-ethyl-3,5-dimethylpyrazine, the rubber-like smelling benzothiazole, the plaster-like smelling 2-bromophenol, the coconut-like smelling $\gamma$-octalactone, the woodruff-like smelling coumarin, the lily-like, faecal smelling indole, and the sandalwood-like smelling $5 \alpha$-androst-16-en-3 $\alpha$-ol. Flavour dilution factors varied between individual samples. Thus, no odorant was found to be of major olfactory importance in all samples. Nonetheless, for certain women, the flavour dilution factors of $(E, Z, Z)-2,4,7$-tridecatrienal, as well as $\beta$-ionone, $(E)$-2-nonenal, and two unidentified compounds were higher in the colostrum samples compared to the corresponding transitional milk samples. Such differences may be explained by the higher carotenoid concentrations [117] and the different fatty acid composition in colostrum, transitional and mature 
milk [118, 119]. Indeed, colostrum from days 1-5 is known to contain high contents of polyunsaturated fatty acids including arachidonic acid [118-121]. The compound $(E, Z, Z)-2,4,7-$ tridecatrienal being a product of autoxidation of this acid [75], its concentration can be expected to be related to its precursor's concentration. Autoxidation products that are specific to certain fatty acid precursors might be a common principle of different fatty acid compositions of colostrum and transitional or mature milk resulting in distinct aroma profiles that might be differentiated by the newborns.

It can be concluded that we are only at the beginning of understanding in which way the lactational stage influences the odour profiles of colostrum and milk. The available evidence supports the hypothesis that the concentration of odorants in breast secretions depends on the lactational stage, and that quantitative changes occur during lactogenesis II, notwithstanding that the majority of milk odorants has been detected in both colostrum and milk. Future research should address the supposed quantitative differences in odorant concentrations via quantification experiments. Thereby, it needs to be kept in mind that colostrum differs from milk in its overall composition which might additionally affect aroma release.

\subsubsection{Maternal exposure to and intake of odorants}

Odorants are most often lipophilic and of low molecular weight and can thus, from our knowledge on drug transfer [122], be expected to pass into milk. Indeed, the odour quality of milk can vary according to the maternal diet, e.g. after consumption of garlic [123], alcohol [124], vanilla [125], carrots [126], 1,8-cineol [127], and after smoking [128, 129]. Mennella and colleagues investigated whether neonates can perceive such differences, and to which extent the different odour qualities may be reflected in infants' discriminative behaviour during breastfeeding [123-125, 129, 130]. These studies have been excellently reviewed $[131,132]$. Hence, only more recent literature, together with research on the chemical bases underlying the aroma transfer into milk, is presented here. 
A common food with characteristic flavour is garlic, and the transfer of its odour into milk has been demonstrated by Mennella \& Beauchamp [123], yet without unravelling the underlying molecular principles. In a more recent study by Scheffler et al. [133], the garlic- and cabbage-like odour in milk samples was detected 2 to 3 hours after consumption of $3 \mathrm{~g}$ raw garlic by the mothers. Using GCO/MS, three garlic-derived compounds were detected in the milk samples, namely allyl methyl sulfide (AMS), allyl methyl sulfoxide (AMSO) and allyl methyl sulfone $\left(\mathrm{AMSO}_{2}\right)$. The maximum concentrations ranged between 1 and $4 \mu \mathrm{g} / \mathrm{kg}, 30$ and $145 \mu \mathrm{g} / \mathrm{kg}$, and 49 and $200 \mu \mathrm{g} / \mathrm{kg}$, respectively [134]. Whereas $\mathrm{AMS}$ has a garlic-like odour, $\mathrm{AMSO}$ and $\mathrm{AMSO}_{2}$ are odourless. Thus, though the natural aroma profile of garlic (a combination of different odorants) was not replicated in milk, one characteristic garlic odorant (AMS) was transferred in amounts perceivable to adults. Similarly, ingestion of $10 \mathrm{~g}$ ramson led to a garlic- and cabbage-like odour of milk and excretion of the same metabolites, with maximum concentrations of AMS, AMSO, and AMSO2 ranging between 1.7 and 2.0 $\mu \mathrm{g} / \mathrm{kg}, 38$ and $90 \mu \mathrm{g} / \mathrm{kg}$, and 53 and $99 \mu \mathrm{g} / \mathrm{kg}$, respectively [135].

In another study, Kirsch and colleagues [127] investigated whether the eucalyptus-like smelling 1,8cineole (eucalyptol), which is the major constituent of a non-prescription pharmaceutical product (Soledum ${ }^{\circledast}$ ), is transferred into milk. Aroma profile analyses indicated that the highest intensity of the eucalyptus-like odour occurred in milk sampled around two hours after ingestion of $100 \mathrm{mg} \mathrm{1,8-}$ cineole (one capsule). This odour was traced back not only to the molecule 1,8-cineole itself but also to several metabolites bearing an eucalyptus-like odour, namely 2,3-dehydro-1,8-cineole, $\alpha 2,3$ epoxy-1,8-cineole, 2-oxo-1,8-cineole, 3-oxo-1,8-cineole, $\alpha 2$-hydroxy-1,8-cineole, $\beta 2$-hydroxy-1,8cineole, $\alpha 3$-hydroxy-1,8-cineole, 4-hydroxy-1,8-cineole, 7-hydroxy-1,8-cineole and 9-hydroxy-1,8cineole [136]. Thereby, the metabolite profiles of 1,8-cineole differed both between individuals as well as between different body fluids [136-139]. Thus, urine mainly contained glucuronides of 1,8cineole metabolites, whereas milk contained the non-conjugated aglycone metabolites.

Individual odorants were also consumed by mothers participating in a study by Hausner et al. [140]. They investigated the transfer of $d$-carvone, I-menthol, trans-anethole and 3-methylbutyl acetate 
into milk after consumption of $100 \mathrm{mg}$ of each odorant in capsules. After around two hours, concentration maxima in milk were determined for $d$-carvone and trans-anethole, whereas I-menthol showed a plateau pattern over several hours. In contrast, the ester 3-methylbutyl acetate was not transferred into milk, at least not in amounts above the detection limit of the method. Yet, the authors provide anecdotal evidence that transfer into milk might occur very fast for this odorant (and hence prior to the first sampling point in that study). Otherwise, the authors raise further possible explanations such as poor solubility in milk fat or hydrolysis in the stomach.

In other studies, no odour transfer into milk was detected. Sandgruber et al. [141] performed experiments on long-term fish oil supplementation in lactating women. In a first step, the odour profile and composition of fish oil were determined by sensory analyses and GC-O/MS. The marker odorants were then screened for in milk samples after the women took part in a defined long-term fish oil supplementation project (starting from the $16^{\text {th }}$ week of gestation, until $4^{\text {th }}$ month postpartum). No statistically significant higher concentrations of the marker odorants were evident in milk samples obtained from mothers supplemented with fish oil, compared to a control group of mothers. However, the diet of the control group's mothers is not specified in that study, and the marker odorants (e.g., saturated aldehydes and ketones) can be expected to occur in other foods as well. Otherwise, Denzer et al. [142] studied the transfer of odorants from commercially available nursing (fennel-anise-caraway) tea into mothers' milk. After identification and quantification of the main terpenes in the tea samples, selected target terpenes were quantified in milk before and after tea consumption by means of GC-MS in combination with stable isotope dilution assays. The terpene concentrations did not significantly increase in milk after tea consumption.

In sum, the evidence available so far is restricted to specific foods and suggests that the aroma profile of the breastfeeding mother's diet is partly transferred into milk, certain molecules being either not transferred or metabolised. Further studies would be important to gain a more comprehensive understanding of the metabolic fate of odorants in the lactating body. For instance, it remains to be investigated whether the metabolism of odorants in general, and hence also their 
transfer into milk, is shaped by genetic or epigenetic factors. Further, it might be worth to evaluate to which extent the milk/plasma concentration ratios or temporal or quantitative aspects of the transfer of odorants into milk can be predicted from the respective chemical structures, e.g. via adapting models derived from research on drug transfer [143].

\section{$\underline{3.3 \text { Conclusions }}$}

From the above-cited studies, it becomes evident that milk is of overall low odour intensity for adult noses but nonetheless comprises a plethora of odorants. It is still unknown whether an odorant out of these, or a combination of odorants, conveys the chemosensory percept of milk odour to the infant and hence induces the behavioural effects summarised in the first part of this review. We further deduce that the aroma of milk is altered by cold storage, and that the extent and nature of aroma changes depends on storage temperature and duration. This finding is not only of theoretical interest but may also be used to optimise storage conditions of expressed milk. Milk odour further varies according to maternal dietary aroma intake, the supposed molecular mechanism being metabolism and exogenous aroma transfer from the plasma. Lactational stage has also been suggested to be reflected by quantitative differences in aroma composition, possibly due to a different pattern of enzymatic processes and substrates. Other factors potentially influencing the odour of milk, e.g., weaning or physical activity, have not yet been addressed in depth. Further, the field still lacks a systematic effort to investigate the detection of milk odour changes by the infant. For this reason, it is unclear whether storage-induced changes are noticed by the infant. The available studies mostly addressed diet-induced milk odour alterations and point towards the detection of such changes by the nursling. This needs to be considered when planning research with the aim of elucidating the role of milk odour in mother-infant interaction.

\section{Future directions}


It is evident that several aspects of research on milk odour deserve closer attention. We therefore aim to elaborate further on selected areas of research that we deem to be of major importance to the field.

\section{$\underline{4.1 \text { Deciphering milk odorant composition and its behaviourally active principles }}$}

Certainly, the first steps have been taken to elucidate the odorant composition of milk. Despite this, however, we still lack quantitative data on the occurrence of odorants in relation to the overall composition of the milk, most notably the fat content (see [144]). This would not only contribute to our basic understanding of milk odour, e.g. via calculation of additional odour activity values, but would also contribute to characterize differences in odorant composition that occur between individuals, or in the context of lactational stage or dynamic changes during a breastfeeding session. Such research might also indicate the origin of certain odour-active compounds (e.g., from the environment, specifically the diet, or from metabolism).

Finally, two aspects related to the communicative value of milk odour remain to be elucidated. First, what makes human milk odour specific to humans? The odour-generating principle beyond amino acid conjugates occurring in human sweat, and having been detected in milk, is one potential candidate for conveying information specific to humans [145], but there might be others. Second, what makes human milk odour specific to a human mother? As reported above, infants behaviourally discriminate between the odours of their own mother's milk and of another mother's milk. It is tempting to assume a signature odour specific to the respective mother as an underlying principle (see [146]). But if so, will this signature odour be disturbed by alterations of milk odour due to dietary aroma intake? And, once learned, can the same signature odour be recognized in other body fluids, e.g. learned in amniotic fluid and recognized in milk odour? And finally, can such a signature odour be determined by the methods described above, or do we need complementary techniques, e.g., those targeting molecules of higher molecular weight?

\subsection{Elucidating the starting point of neonatal responses to milk odour}


In view of the crucial need of the newborn to gain access to colostrum, best during the first hour postpartum $[3,147]$, an adaptive behavioural interaction between the mother and the neonate can be supposed to occur right after birth. Thus, maternal odours may elicit and modulate infantile behaviours and states in a way that favours successful birth transition and that conserves energy in the mother-infant dyad. As outlined above, the odours of colostrum and milk do indeed promote sucking and intake, and have a soothing effect on infants experiencing distress or pain. Yet, is this set of responses present right at birth, or is it the result of some kind of postnatal learning? Due to ethical and practical reasons, this question has been addressed very seldom. One of the rare studies having investigated neonatal behaviour towards the odour of milk before the first breastfeeding experience was accomplished by Marlier et al. in 1997 [7]. In a double-choice test with 9 neonates, of whom 6 were without any breastfeeding experience (and 3 just exposed to mother's breast in the labour room), no discriminative behaviour towards familiar amniotic fluid and familiar colostrum was evident, supporting the hypothesis of transnatal chemosensory continuity between the amniotic and milk environments (see $[148,149]$, for reviews). Further, indirect evidence comes from studies with bottle-fed neonates. Thus, as outlined above, 1-day-old bottle-fed neonates evinced longer mouthing movements in response to unfamiliar and familiar milk compared with formula, water, and orange juice [20]. Even after 3 days of formula feeding, neonates further showed a preferential head orientation and longer mouthing towards the odour of unfamiliar milk compared to the odour of the familiar formula [11]. However, this is indirect evidence. Direct evidence on how newly-born neonates react to milk odour is still missing. Therefore, future experiments are needed to answer the question of how the odour of milk is involved in very early adaptive maternal-infantile interactions.

Funding: This work was funded by the Free State of Bavaria (Bavarian Equal Opportunities Sponsorship - Förderung von Frauen in Forschung und Lehre (FFL)- Promoting Equal Opportunities for Women in Research and Teaching), the French National Research Agency, the Regional Council of Bourgogne, and the Centre National de la Recherche Scientifique. 
Acknowledgements: The authors would like to thank Constanze Sharapa, Friedrich-Alexander-

Universität Erlangen-Nürnberg, Germany, for inspiring discussions and comments on the manuscript. 
References

[1] Schaal, B., Doucet, S., Soussignan, R., Rietdorf, M., Weibchen, G., Francke, W. The human breast as a scent organ: Exocrine structures, secretions, volatile components, and possible functions in breastfeeding interactions. In: Hurst JL, Beynon RJ, Roberts SC, Wyatt TD, eds. Chem Signals Vertebr. New York: Springer; 2008. p. 325-35.

[2] Schaal, B. Mammary odor cues and pheromones: mammalian infant-directed communication about maternal state, mammae, and milk. Vitamins and Hormones: Pheromones 2010. p. 83-136. [3] Schaal, B., Al Aïn, S. Chemical signals 'selected for' newborns in mammals. Anim. Behav. 2014, 97:289-99. doi: 10.1016/j.anbehav.2014.08.022.

[4] Macfarlane, A. Olfaction in the development of social preferences in the human neonate. Ciba Found. Symp. 1975, 33:103-17.

[5] Marlier, L., Schaal, B., Soussignan, R. Neonatal responsiveness to the odor of amniotic and lacteal fluids: A test of perinatal chemosensory continuity. Child Dev. 1998, 69:611-23. doi: 10.1111/j.14678624.1998.tb06232.x.

[6] Marlier, L., Schaal, B. Familiarité et discrimination olfactive chez le nouveau-né: influence différentielle du mode d'alimentation? Enfance. 1997, 1:47-61.

[7] Marlier, L., Schaal, B., Soussignan, R. Orientation responses to biological odours in the human newborn. Initial pattern and postnatal plasticity. C R Acad Sci Ser III Sci Vie. 1997, 320:999-1005. doi: 10.1016/S0764-4469(97)82473-0.

[8] Marlier, L., Schaal, B., Soussignan, R. Bottle-fed neonates prefer an odor experienced in utero to an odor experienced postnatally in the feeding context. Dev. Psychobiol. 1998, 33:133-45. doi: 10.1002/(SICI)1098-2302(199809)33:2<133::AID-DEV4>3.0.CO;2-K. 
[9] Schaal, B., Coureaud, G., Marlier, L., Soussignan, R. Fetal olfactory cognition preadapts neonatal behavior in mammals. In: Marchlewska-Koj A, Lepri JJ, Müller-Schwarze D, eds. Chem Signals Vertebr. New York: Kluwer Academic/Plenum Publishers; 2001. p. 197-204.

[10] Delaunay-El Allam, M. D. E. L'expérience sensorielle du nouveau-né et sa rétention à long terme: une analyse expérimentale de l'apprentissage des odeurs chez l'enfant humain [Thèse de doctorat]. Dijon: Université de Bourgogne; 2007.

[11] Marlier, L., Schaal, B. Human newborns prefer human milk: Conspecific milk odor is attractive without postnatal exposure. Child Dev. 2005, 76:155-68. doi: 10.1111/j.1467-8624.2005.00836.x. [12] Delaunay-El Allam, M. D. E., Marlier, L., Schaal, B. Learning at the breast: Preference formation for an artificial scent and its attraction against the odor of maternal milk. Infant Behav. Dev. 2006, 29:308-21. doi: 10.1016/j.infbeh.2005.12.008.

[13] Bingham, P. M., Abassi, S., Sivieri, E. A pilot study of milk odor effect on nonnutritive sucking by premature newborns. Arch. Pediatr. Adolesc. Med. 2003, 157:72-5. doi: 10.1001/archpedi.157.1.72. [14] Raimbault, C., Saliba, E., Porter, R. H. The effect of the odour of mother's milk on breastfeeding behaviour of premature neonates. Acta Paediatr. 2007, 96:368-71. doi: 10.1111/j.16512227.2007.00114.x.

[15] Mizuno, K., Ueda, A. Antenatal olfactory learning influences infant feeding. Early Hum. Dev. 2004, 76:83-90. doi: 10.1016/j.earlhumdev.2003.10.003.

[16] Johnson, P., Salisbury, D. M. Breathing and sucking during feeding in the newborn. In: Porter R, O'Connor M, eds. Ciba Foundation Symposium 33 - Parent-Infant Interaction. Amsterdam: Elsevier; 1975. p. $119-35$.

[17] Mathew, O. P., Bhatia, J. Sucking and breathing patterns during breast- and bottle-feeding in term neonates: Effects of nutrient delivery and composition. Am. J. Dis. Child. 1989, 143:588-92. doi: 10.1001/archpedi.1989.02150170090030.

[18] Mizuno, K., Ueda, A., Takeuchi, T. Effects of different fluids on the relationship between swallowing and breathing during nutritive sucking in neonates. Neonatology. 2002, 81:45-50. doi: $10.1159 / 000047183$. 
[19] Doucet, S., Soussignan, R., Sagot, P., Schaal, B. The "smellscape" of mother's breast: Effects of odor masking and selective unmasking on neonatal arousal, oral, and visual responses. Dev.

Psychobiol. 2007, 49:129-38. doi: 10.1002/dev.20210.

[20] Mizuno, K., Mizuno, N., Shinohara, T., Noda, M. Mother-infant skin-to-skin contact after delivery results in early recognition of own mother's milk odour. Acta Paediatr. 2004, 93:1640-5. doi: 10.1111/j.1651-2227.2004.tb00856.x.

[21] Soussignan, R., Schaal, B., Marlier, L., Jiang, T. Facial and autonomic responses to biological and artificial olfactory stimuli in human neonates: Re-examining early hedonic discrimination of odors. Physiol. Behav. 1997, 62:745-58. doi: 10.1016/S0031-9384(97)00187-X.

[22] Oster, H., Ekman, P. Facial behavior in child development. In: Collins A, ed. Minnesota symposia on child psychology. Hillsdale, NJ: Lawrence Erlbaum Ass.; 1978. p. 231-76.

[23] Rosenblatt, J. S. Olfaction mediates developmental transition in the altricial newborn of selected species of mammals. Dev. Psychobiol. 1983, 16:347-75. doi: 10.1002/dev.420160502.

[24] Doucet, S., Soussignan, R., Sagot, P., Schaal, B. The secretion of areolar (Montgomery's) glands from lactating women elicits selective, unconditional responses in neonates. PLoS One. 2009, 4:e7579. doi: 10.1371/journal.pone.0007579.

[25] Loos, H. M., Doucet, S., Soussignan, R., Hartmann, C., Durand, K., Dittrich, R., Sagot, P., Buettner, A., Schaal, B. Responsiveness of human neonates to the odor of $5 \alpha$-androst-16-en-3-one: a behavioral paradox? Chem. Senses. 2014, 39:693-703. doi: 10.1093/chemse/bju041.

[26] Loos, H. M., Doucet, S., Védrines, F., Sharapa, C., Soussignan, R., Durand, K., Sagot, P., Buettner, A., Schaal, B. Responses of human neonates to highly diluted odorants from sweat. J. Chem. Ecol. 2017, 43:106-17. doi: 10.1007/s10886-016-0804-x.

[27] Doty, R. An examination of relationships between the pleasantness, intensity, and concentration of 10 odorous stimuli. P\&P. 1975, 17:492-6. doi: 10.3758/BF03203300.

[28] Laing, D. G., Legha, P. K., Jinks, A. L., Hutchinson, I. Relationship between molecular structure, concentration and odor qualities of oxygenated aliphatic molecules. Chem. Senses. 2003, 28:57-69. doi: 10.1093/chemse/28.1.57. 
[29] Wright, G. A., Thomson, M. G. A., Smith, B. H. Odour concentration affects odour identity in honeybees. Proc R Soc Biol Sci Ser B. 2005, 272:2417-22. doi: 10.1098/rspb.2005.3252.

[30] Cleland, T., Chen, S.-Y., Hozer, K., Ukatu, H., Wong, K., Zheng, F. Sequential mechanisms underlying concentration invariance in biological olfaction. Front. Neuroeng. 2012, 4. doi: 10.3389/fneng.2011.00021.

[31] Hartlieb, E., Anton, S., Hansson, B. S. Dose-dependent response characteristics of antennal lobe neurons in the male moth Agrotis segetum (Lepidoptera: Noctuidae). J. Comp. Physiol., A. 1997, 181:469-76. doi: 10.1007/s003590050130.

[32] Coureaud, G., Langlois, D., Sicard, G., Schaal, B. Newborn rabbit responsiveness to the mammary pheromone is concentration-dependent. Chem. Senses. 2004, 29:341-50. doi:

10.1093/chemse/bjh037.

[33] Bartocci, M., Winberg, J., Ruggiero, C., Bergqvist, L. L., Serra, G., Lagercrantz, H. Activation of olfactory cortex in newborn infants after odor stimulation: A functional near-infrared spectroscopy study. Pediatr. Res. 2000, 48:18-23.

[34] Aoyama, S., Tamotsu, T., Yuri, S., Nakao, K., Kyoko, M., Nobutsune, I., Kazuhiro, N., Masao, K. Maternal breast milk odour induces frontal lobe activation in neonates: A NIRS study. Early Hum. Dev. 2010, 86:541-5. doi: 10.1016/j.earlhumdev.2010.07.003.

[35] Baudesson de Chanville, A., Brevaut-Malaty, V., Garbi, A., Tosello, B., Baumstarck, K., Gire, C. Analgesic effect of maternal human milk odor on premature neonates: a randomized controlled trial. J. Hum. Lact. 2017, 33:300-8. doi: 10.1177/0890334417693225.

[36] Nishitani, S., Miyamura, T., Tagawa, M., Sumi, M., Takase, R., Doi, H., Moriuchi, H., Shinohara, K. The calming effect of a maternal breast milk odor on the human newborn infant. Neurosci. Res. 2009, 63:66-71. doi: 10.1016/j.neures.2008.10.007.

[37] Badiee, Z., Asghari, M., Mohammadizadeh, M. The calming effect of maternal breast milk odor on premature infants. Pediatr. Neonatol. 2013, 54:322-5. doi: 10.1016/j.pedneo.2013.04.004.

[38] Goubet, N., Rattaz, U., Pierrat, W., Bullinger, A., Lequien, P. Olfactory experience mediates response to pain in preterm newborns. Dev. Psychobiol. 2003, 42:171-80. doi: 10.1002/dev.10085. 
[39] Rattaz, C., Goubet, N., Bullinger, A. The calming effect of a familiar odor on full-term newborns.

J. Dev. Behav. Pediatr. 2005, 26:86-92.

[40] Neshat, H., Jebreili, M., Seyyedrasouli, A., Ghojazade, M., Hosseini, M. B., Hamishehkar, H.

Effects of breast milk and vanilla odors on premature neonate's heart rate and blood oxygen saturation during and after venipuncture. Pediatr. Neonatol. 2016, 57:225-31. doi: 10.1016/j.pedneo.2015.09.004.

[41] Mellier, D., Bezard, S., Caston, J. Études exploratoires des relations intersensorielles olfactiondouleur. Enfance. 1997:98-111.

[42] Sullivan, R. M., Taborskybarba, S., Mendoza, R., Itano, A., Leon, M., Cotman, C. W., Payne, T. F., Lott, I. Olfactory classical-conditioning in neonates. Pediatrics. 1991, 87:511-8.

[43] Varendi, H., Porter, R. H., Winberg, J. The effect of labor on olfactory exposure learning within the first postnatal hour. Behav. Neurosci. 2002, 116:206-11. doi: 10.1037/0735-7044.116.2.206. [44] Delaunay-El Allam, M. D. E., Soussignan, R., Patris, B., Marlier, L., Schaal, B. Long-lasting memory for an odor acquired at the mother's breast. Dev Sci. 2010, 13:849-63. doi: 10.1111/j.14677687.2009.00941.x.

[45] Romantshik, O., Porter, R., Tillmann, V., Varendi, H. Preliminary evidence of a sensitive period for olfactory learning by human newborns. Acta Paediatr. 2007, 96:372-6. doi: 10.1111/j.16512227.2006.00106.x.

[46] Harzer, G. Über die Zusammensetzung der Muttermilch - Zur Adaption von Säuglingsmilchnahrungen [Doctoral Thesis]. Gießen: Justus-Liebig-Universität Gießen; 1989. [47] Coppa, G. V., Pierani, P., Zampini, L., Carloni, I., Carlucci, A., Gabrielli, O. Oligosaccharides in human milk during different phases of lactation. Acta Pædiatrica. 1999, 88:89-94. doi: 10.1111/j.1651-2227.1999.tb01307.x.

[48] Hampel, D., Shahab-Ferdows, S., Islam, M. M., Peerson, J. M., Allen, L. H. Vitamin concentrations in human milk vary with time within feed, circadian rhythm, and single-dose supplementation. J.

Nutr. 2017, 147:603-11. doi: 10.3945/jn.116.242941. 
[49] Zhang, Z., Adelman, A. S., Rai, D., Boettcher, J., Lonnerdal, B. Amino acid profiles in term and preterm human milk through lactation: a systematic review. Nutrients. 2013, 5:4800-21. doi: $10.3390 /$ nu5124800.

[50] Bardanzellu, F., Fanos, V., Reali, A. "Omics" in human colostrum and mature milk: looking to old data with new eyes. Nutrients. 2017, 9:24. doi: 10.3390/nu9080843.

[51] Weber, J. A., Baxter, D. H., Zhang, S. L., Huang, D. Y., Huang, K. H., Lee, M. J., Galas, D. J., Wang, K. The microRNA spectrum in 12 body fluids. Clin. Chem. 2010, 56:1733-41. doi:

10.1373/clinchem.2010.147405.

[52] Hassiotou, F., Geddes, D. Anatomy of the human mammary gland: Current status of knowledge. Clin. Anat. 2013, 26:29-48. doi: 10.1002/ca.22165.

[53] Lönnerdal, B. Nutritional and physiologic significance of human milk proteins. Am. J. Clin. Nutr. 2003, 77:1537S-43S. doi: 10.1093/ajcn/77.6.1537S.

[54] Demmelmair, H., Prell, C., Timby, N., Lonnerdal, B. Benefits of lactoferrin, osteopontin and milk fat globule membranes for infants. Nutrients. 2017, 9. doi: 10.3390/nu9080817.

[55] Keenan, T. W. Milk lipid globules and their surrounding membrane: A brief history and perspectives for future research. J. Mammary Gland Biol. Neoplasia. 2001, 6:365-71. doi: 10.1023/a:1011383826719.

[56] Koletzko, B., Agostoni, C., Bergmann, R., Ritzenthaler, K., Shamir, R. Physiological aspects of human milk lipids and implications for infant feeding: a workshop report. Acta Paediatr. 2011, 100:1405-15. doi: 10.1111/j.1651-2227.2011.02343.x.

[57] Bode, L. Human milk oligosaccharides: Every baby needs a sugar mama. Glycobiology. 2012, 22:1147-62. doi: 10.1093/glycob/cws074.

[58] Bates, C. J., Prentice, A. Breast milk as a source of vitamins, essential minerals and traceelements. Pharmacol. Ther. 1994, 62:193-220. doi: 10.1016/0163-7258(94)90011-6.

[59] Klein, L. D., Breakey, A. A., Scelza, B., Valeggia, C., Jasienska, G., Hinde, K. Concentrations of trace elements in human milk: Comparisons among women in Argentina, Namibia, Poland, and the United States. PLoS One. 2017, 12:16. doi: 10.1371/journal.pone.0183367. 
[60] McManaman, J. L., Neville, M. C. Mammary physiology and milk secretion. Adv. Drug Del. Rev. 2003, 55:629-41. doi: 10.1016/s0169-409x(03)00033-4.

[61] Stafford, M., Horning, M. G., Zlatkis, A. Profiles of volatile metabolites in body fluids. J. Chromatogr. 1976, 126:495-502. doi: 10.1016/S0021-9673(01)84096-6.

[62] Pellizzari, E. D., Hartwell, T. D., Harris, B. S. H., Waddell, R. D., Whitaker, D. A., Erickson, M. D. Purgeable organic compounds in mother's milk. Bull. Environ. Contam. Toxicol. 1982, 28:322-8. doi: 10.1007/BF01608515.

[63] Lichtenberger, L. M., Gardner, J. W., Barreto, J. C., Morrissv, F. H. J. Evidence for a role of volatile amines in the development of neonatal hypergastrinemia. J. Pediatr. Gastroenterol. Nutr. 1991, 13:342-6.

[64] Shimoda, M., Yoshimura, T., Ishikawa, H., Hayakawa, I., Osajima, Y. Volatile compounds of human milk. J Fac Agric Kyushu Univ. 2000, 45:199-206.

[65] Kim, S. R., Halden, R. U., Buckley, T. J. Volatile organic compounds in human milk: methods and measurements. Environ. Sci. Technol. 2007, 41:1662-7. doi: 10.1021/es062362y.

[66] Hausner, H., Philipsen, M., Skov, T. H., Petersen, M. A., Bredie, W. L. P. Characterization of the volatile composition and variations between infant formulas and mother's milk. Chemosensory Perception. 2009, 2:79-93. doi: 10.1007/s12078-009-9044-6.

[67] Weibchen, G. Identifizierung und Synthese flüchtiger Verbindungen aus Vertebraten [Doctoral Thesis]. Hamburg: Universität Hamburg; 2010.

[68] Contreras, C. M., Gutiérrez-García, A. G., Mendoza-López, R., Rodríguez-Landa, J. F., BernalMorales, B., Díaz-Marte, C. Amniotic fluid elicits appetitive responses in human newborns: Fatty acids and appetitive responses. Dev. Psychobiol. 2013, 55:221-31. doi: 10.1002/dev.21012.

[69] Contador, R., Delgado, F. J., García-Parra, J., Garrido, M., Ramírez, R. Volatile profile of breast milk subjected to high-pressure processing or thermal treatment. Food Chem. 2015, 180:17-24. doi: 10.1016/j.foodchem.2015.02.019. 
[70] Garrido, M., Contador, R., García-Parra, J., Delgado, F. J., Delgado-Adámez, J., Ramírez, R. Volatile profile of human milk subjected to high-pressure thermal processing. Food Res. Int. 2015, 78:186-94. doi: 10.1016/j.foodres.2015.10.016.

[71] Hartmann, C., Doucet, S., Niclass, Y., Dittrich, R., Cupisti, S., Schaal, B., Buettner, A., Starkenmann, C. Human sweat odour conjugates in human milk, colostrum and amniotic fluid. Food Chem. 2012, 135:228-33. doi: 10.1016/j.foodchem.2012.04.077.

[72] Fuller, G. H., Steltenkamp, R., Tisserand, G. A. The gas chromatograph with human sensor: perfumer model. Ann. N. Y. Acad. Sci. 1964, 116:711-24. doi: 10.1111/j.1749-6632.1964.tb45106.x. [73] van Ruth, S. M. Methods for gas chromatography-olfactometry: a review. Biomol. Eng. 2001, 17:121-8. doi: 10.1016/S1389-0344(01)00070-3.

[74] Ullrich, F., Grosch, W. Identification of the most intense volatile flavour compounds formed during autoxidation of linoleic acid. Z. Lebensm. Unters. Forsch. 1987, 184:277-82. doi:

\subsection{7/bf01027663.}

[75] Blank, I., Lin, J., Vera, F. A., Welti, D. H., Fay, L. B. Identification of potent odorants formed by autoxidation of arachidonic acid: structure elucidation and synthesis of (E,Z,Z)-2,4,7-tridecatrienal. J. Agric. Food Chem. 2001, 49:5959-65. doi: 10.1021/jf010160+.

[76] Ayers, J. E., Fishwick, M. J., Land, D. G., Swain, T. Off-flavor of dehydrated carrot stored in oxygen. Nature. 1964, 203:81-2. doi: 10.1038/203081a0.

[77] Sanderson, G. W., Co, H., Gonzalez, J. G. Biochemistry of tea fermentation: the role of carotenes in black tea aroma-formation. J. Food Sci. 1971, 36:231-6. doi: 10.1111/j.1365-2621.1971.tb04031.x. [78] Lewis, T. R., Emery, R. S. Intermediate products in the catabolism of amino acids by rumen microorganisms. J. Dairy Sci. 1962, 45:1363-8. doi: 10.3168/jds.S0022-0302(62)89627-1. [79] Schieberle, P. The role of free amino-acids present in yeast as percursors of the odorants 2acetyl-1-pyrroline and 2-acetyltetrahydropyridine in wheat bread crust Z. Lebensm. Unters. Forsch. 1990, 191:206-9. doi: 10.1007/bf01197621.

[80] Schwarzbauer, J., Heim, S. Lipophilic organic contaminants in the Rhine river, Germany. Water Res. 2005, 39:4735-48. doi: 10.1016/j.watres.2005.09.029. 
[81] Oliveira, A. S., Silva, V. M., Veloso, M. C. C., Santos, G. V., Andrade, J. B. d. Bromophenol concentrations in fish from Salvador, BA, Brazil. An. Acad. Bras. Cienc. 2009, 81:165-72. doi: $10.1590 /$ S0001-37652009000200002.

[82] Buettner, A. A selective and sensitive approach to characterize odour-active and volatile constituents in small-scale human milk samples. Flavour Fragrance J. 2007, 22:465-73. doi: 10.1002/ffj.1822.

[83] Spitzer, J. Aromaveränderung von Muttermilch während der Lagerung [Doctoral Thesis]. Erlangen: Friedrich-Alexander-Universität Erlangen-Nürnberg; 2013.

[84] Spitzer, J., Buettner, A. Aromastabilität von Muttermilch während der Lagerung bei $-20^{\circ} \mathrm{C}$. Aktuelle Wochenschau GDCh. 2009.

[85] Spitzer, J., Buettner, A. Characterization of aroma changes in human milk during storage at $19^{\circ}$ C. Food Chem. 2010, 120:240-6. doi: 10.1016/j.foodchem.2009.10.015.

[86] Bingham, P. M., Stevens-Tuttle, D., Lavin, E., Acree, T. Odorants in breast milk. Arch. Pediatr. Adolesc. Med. 2003, 157:1031. doi: 10.1001/archpedi.157.10.1031.

[87] Loos, H. Ethological and aroma-analytical investigations on human milk odour [Doctoral Thesis]. Erlangen: Friedrich-Alexander-Universität Erlangen-Nürnberg; 2015.

[88] Hartmann, C., Mayenzet, F., Larcinese, J.-P., Haefliger, O. P., Buettner, A., Starkenmann, C. Development of an analytical approach for identification and quantification of $5 \alpha$-androstenone in human milk. Steroids. 2013, 78:156-60. doi: 10.1016/j.steroids.2012.11.005.

[89] Sandgruber, S., Much, D., Amann-Gassner, U., Hauner, H., Buettner, A. Sensory and molecular characterisation of the protective effect of storage at $-80^{\circ} \mathrm{C}$ on the odour profiles of human milk. Food Chem. 2012, 130:236-42. doi: 10.1016/j.foodchem.2011.07.013.

[90] Spitzer, J., Buettner, A. Monitoring aroma changes during human milk storage at $-90^{\circ} \mathrm{C}$ by quantification experiments. Food Res. Int. 2013, 51:250-6. doi: 10.1016/j.foodres.2012.12.002. [91] Rothe, M., Thomas, B. Aromastoffe des Brotes. Z. Lebensm. Unters. Forsch. 1963, 119:302-10. doi: 10.1007/BF01891082. 
[92] Spitzer, J., Klos, K., Buettner, A. Monitoring aroma changes during human milk storage at $+4{ }^{\circ} \mathrm{C}$ by sensory and quantification experiments. Clin. Nutr. 2013, 32:1036-42. doi:

10.1016/j.clnu.2013.01.015.

[93] Frijters, J. E. R. A critical analysis of the odour unit number and its use. Chem. Senses. 1978, 3:227-33. doi: 10.1093/chemse/3.2.227.

[94] Grosch, W. Evaluation of the key odorants of foods by dilution experiments, aroma models and omission. Chem. Senses. 2001, 26:533-45. doi: 10.1093/chemse/26.5.533.

[95] Hall, B. Changing composition of human milk and early development of an appetite control. Lancet. 1975, 5:779-81. doi: 10.1016/S0140-6736(75)92440-X.

[96] McDaniel, M. R., Barker, E., Lederer, C. L. Sensory characterization of human milk. J. Dairy Sci. 1989, 72:1149-58. doi: 10.3168/jds.S0022-0302(89)79218-3.

[97] Karatas, Z., Aydogdu, S. D., Dinleyici, E. C., Colak, O., Dogruel, N. Breastmilk ghrelin, leptin, and fat levels changing foremilk to hindmilk: is that important for self-control of feeding? Eur. J. Pediatr. 2011, 170:1273-80. doi: 10.1007/s00431-011-1438-1.

[98] Miller, E. M., Aiello, M. O., Fujita, M., Hinde, K., Milligan, L., Quinn, E. A. Field and laboratory methods in human milk research. Am. J. Hum. Biol. 2013, 25:1-11. doi: 10.1002/ajhb.22334. [99] Andreas, N. J., Kampmann, B., Le-Doare, K. M. Human breast milk: A review on its composition and bioactivity. Early Hum. Dev. 2015, 91:629-35. doi: 10.1016/j.earlhumdev.2015.08.013.

[100] Gardner, A. S., Rahman, I. A., Lai, C. T., Hepworth, A., Trengove, N., Hartmann, P. E., Geddes, D. T. Changes in fatty acid composition of human milk in response to cold-like symptoms in the lactating mother and infant. Nutrients. 2017, 9:7. doi: 10.3390/nu9091034.

[101] Su, L. L., Sk, T. C., Lim, S. L., Chen, Y. M., Tan, E. A. T., Pai, N. N., et al. The influence of maternal ethnic group and diet on breast milk fatty acid composition. Ann. Acad. Med. Singapore. 2010, 39:675-9.

[102] De Luca, A., Hankard, R., Alexandre-Gouabau, M.-C., Ferchaud-Roucher, V., Darmaun, D., Boquien, C.-Y. Higher concentrations of branched-chain amino acids in breast milk of obese mothers. Nutrition. 2016, 32:1295-8. doi: 10.1016/j.nut.2016.05.013. 
[103] Manger, L., Mimouni, F. B., Feinstein-Goren, N., Lubetzky, R., Mandel, D., Marom, R. The effect of maternal habitus on macronutrient content of human milk colostrum. J. Perinatol. 2017, 37:81821. doi: 10.1038/jp.2017.51.

[104] Illnerová, H., Buresová, M., Presl, J. Melatonin rhythm in human milk. J. Clin. Endocrinol. Metab. 1993, 77:838-41. doi: 10.1210/jcem.77.3.8370707.

[105] Wallace, J. P., Inbar, G., Ernsthausen, K. Infant acceptance of postexercise breast milk. Pediatrics. 1992, 89:1245-7.

[106] Carey, G. B., Quinn, T. J., Goodwin, S. E. Breast milk composition after exercise of different intensities. J. Hum. Lact. 1997, 13:115-20. doi: 10.1177/089033449701300211.

[107] Wright, K. S., Quinn, T. J., Carey, G. B. Infant acceptance of breast milk after maternal exercise. Pediatrics. 2002, 109:585-9. doi: 10.1542/peds.109.4.585.

[108] Lawrence, R. A. Storage of human milk and the influence of procedures on immunological components of human milk. Acta Pædiatrica. 1999, 88:14-8. doi: 10.1111/j.1651-

2227.1999.tb01295.x.

[109] Peila, C., Moro, G., Bertino, E., Cavallarin, L., Giribaldi, M., Giuliani, F., Cresi, F., Coscia, A. The effect of holder pasteurization on nutrients and biologically-active components in donor human milk: a review. Nutrients. 2016, 8:477. doi: 10.3390/nu8080477.

[110] Barker, E. Sensory characterization of human milk [Doctoral Thesis]. Manitoba, Winnipeg: University of Manitoba; 1980.

[111] Jiang, T., Schaal, B., Marlier, L., Soussignan, R. The food-related odor environment of French newborns: human and formula milk odors compared by adult nose. Chem. Senses. 1999, 24. [112] Spitzer, J., Doucet, S., Buettner, A. The influence of storage conditions on flavour changes in human milk. Food Qual. Prefer. 2010, 21:998-1007. doi: 10.1016/j.foodqual.2010.05.007. [113] Mennella, J. A., Lukasewycz, L. D., Castor, S. M., Beauchamp, G. K. The timing and duration of a sensitive period in human flavor learning: a randomized trial. Am. J. Clin. Nutr. 2011, 93:1019-24. doi: 10.3945/ajcn.110.003541. 
[114] Hung, H.-Y., Hsu, Y.-Y., Chang, Y.-J. Comparison of physiological and behavioral responses to fresh and thawed breastmilk in premature infants - a preliminary study. Breastfeed. Med. 2013, 8:928. doi: 10.1089/bfm.2012.0026.

[115] Neville, M. C., Allen, J. C., Archer, P. C., Casey, C. E., Seacat, J., Keller, R. P., Lutes, V., Rasbach, J., Neifert, M. Studies in human lactation: milk volume and nutrient composition during weaning and lactogenesis. Am. J. Clin. Nutr. 1991, 54:81-92. doi: 10.1093/ajcn/54.1.81.

[116] Rietdorf, M. Identifizierung und Synthese flüchtiger Substanzen aus Säugetieren [Doctoral Thesis]. Hamburg: University of Hamburg; 2002.

[117] Song, B. J., Jouni, Z. E., Ferruzzi, M. G. Assessment of phytochemical content in human milk during different stages of lactation. Nutrition. 2013, 29:195-202. doi: 10.1016/j.nut.2012.07.015. [118] Harzer, G., Haug, M., Dieterich, I., Gentner, P. R. Changing patterns of human milk lipids in the course of the lactation and during the day. Am. J. Clin. Nutr. 1983, 37:612-21.

[119] Molto-Puigmarti, C., Castellote, A. I., Carbonell-Estrany, X., Lopez-Sabater, M. C. Differences in fat content and fatty acid proportions among colostrum, transitional, and mature milk from women delivering very preterm, preterm, and term infants. Clin. Nutr. 2011, 30:116-23. doi: 10.1016/j.clnu.2010.07.013.

[120] Gibson, R. A., Kneebone, G. M. Fatty acid composition of human colostrum and mature breast milk. Am. J. Clin. Nutr. 1981, 34:252-7. doi: 10.1093/ajcn/34.2.252.

[121] Zou, X.-Q., Guo, Z., Huang, J.-H., Jin, Q.-Z., Cheong, L.-Z., Wang, X.-G., Xu, X.-B. Human milk fat globules from different stages of lactation: A lipid composition analysis and microstructure characterization. J. Agric. Food Chem. 2012, 60:7158-67. doi: 10.1021/jf3013597. [122] Friguls, B., Joya, X., Garcia-Algar, O., Pallas, C. R., Vall, O., Pichini, S. A comprehensive review of assay methods to determine drugs in breast milk and the safety of breastfeeding when taking drugs. Anal. Bioanal. Chem. 2010, 397:1157-79. doi: 10.1007/s00216-010-3681-0.

[123] Mennella, J. A., Beauchamp, G. K. Maternal diet alters the sensory qualities of human milk and the nursling's behavior. Pediatrics. 1991, 88:737-44. 
[124] Mennella, J. A., Beauchamp, G. K. The transfer of alcohol to human milk. New Engl. J. Med. 1991, 325:981-5. doi: doi:10.1056/NEJM199110033251401.

[125] Mennella, J. A., Beauchamp, G. K. The human infants' response to vanilla flavors in mother's milk and formula. Infant Behav. Dev. 1996, 19:13-9.

[126] Mennella, J. A., Beauchamp, G. K. Experience with a flavor in mother's milk modifies the infant's acceptance of flavored cereal. Dev. Psychobiol. 1999, 35:197-203. doi: 10.1002/(sici)10982302(199911)35:3<197::aid-dev4>3.0.co;2-j.

[127] Kirsch, F., Horst, K., Roehrig, W., Rychlik, M., Buettner, A. Tracing metabolite profiles in human milk: studies on the odorant 1,8-cineole transferred into breast milk after oral intake. Metabolomics. 2013, 9:483-96. doi: 10.1007/s11306-012-0466-9.

[128] Mennella, J. A., Beauchamp, G. K. Smoking and the flavor of breast milk. New Engl. J. Med. 1998, 339:1559-60. doi: doi:10.1056/NEJM199811193392119.

[129] Mennella, J. A., Yourshaw, L. M., Morgan, L. K. Breastfeeding and smoking: short-term effects on infant feeding and sleep. Pediatrics. 2007, 120:497-502. doi: 10.1542/peds.2007-0488.

[130] Mennella, J. A., Beauchamp, G. K. The effects of repeated exposure to garlic-flavored milk on the nursling's behavior. Pediatr. Res. 1993, 34:805-8. doi: 10.1203/00006450-199312000-00022. [131] Mennella, J. A. Ontogeny of taste preferences: basic biology and implications for health. The American Journal of Clinical Nutrition. 2014, 99:704S-11S. doi: 10.3945/ajcn.113.067694.

[132] Mennella, J. A. Mother's milk: a medium for early flavor experiences. J. Hum. Lact. 1995, 11:3945. doi: $10.1177 / 089033449501100122$.

[133] Scheffler, L., Sauermann, Y., Zeh, G., Hauf, K., Heinlein, A., Sharapa, C., Buettner, A. Detection of volatile metabolites of garlic in human breast milk. Metabolites. 2016, 6:18. doi: 10.3390/metabo6020018.

[134] Scheffler, L., Sharapa, C., Buettner, A. Quantification of volatile metabolites derived from garlic in human breast milk. Food Chem. 2019, 274:603-10. doi:

https://doi.org/10.1016/i.foodchem.2018.09.039. 
[135] Scheffler, L., Sharapa, C., Amar, T., Buettner, A. Identification and Quantification of Volatile Ramson-Derived Metabolites in Humans. Frontiers in Chemistry. 2018, 6. doi:

10.3389/fchem.2018.00410.

[136] Kirsch, F., Buettner, A. Characterisation of the metabolites of 1,8-cineole transferred into human milk: concentrations and ratio of enantiomers. Metabolites. 2013, 3:47-71. doi: 10.3390/metabo3010047.

[137] Horst, K., Rychlik, M. Quantification of 1,8-cineole and of its metabolites in humans using stable isotope dilution assays. Mol. Nutr. Food Res. 2010, 54:1515-29. doi: doi:10.1002/mnfr.200900528. [138] Kirsch, F., Beauchamp, J., Buettner, A. Time-dependent aroma changes in breast milk after oral intake of a pharmacological preparation containing 1,8-cineole. Clin. Nutr. 2012, 31:682-92. doi: 10.1016/j.clnu.2012.02.002.

[139] Schaffarczyk, M., Balaban, T. S., Rychlik, M., Buettner, A. Syntheses of chiral 1,8-cineole metabolites and determination of their enantiomeric composition in human urine after ingestion of 1,8-cineole-containing capsules. ChemPlusChem. 2013, 78:77-85. doi: 10.1002/cplu.201200253. [140] Hausner, H., Bredie, W. L. P., Molgaard, C., Petersen, M. A., Moller, P. Differential transfer of dietary flavour compounds into human breast milk. Physiol. Behav. 2008, 95:118-24. doi: 10.1016/j.physbeh.2008.05.007.

[141] Sandgruber, S., Much, D., Amann-Gassner, U., Hauner, H., Buettner, A. Sensory and molecular characterisation of human milk odour profiles after maternal fish oil supplementation during pregnancy and breastfeeding. Food Chem. 2011, 128:485-94. doi: 10.1016/j.foodchem.2011.03.058. [142] Denzer, M. Y., Kirsch, F., Buettner, A. Are odorant constituents of herbal tea transferred into human milk? J. Agric. Food Chem. 2015, 63:104-11. doi: 10.1021/jf504073d. [143] Abraham, M. H., Gil-Lostes, J., Fatemi, M. Prediction of milk/plasma concentration ratios of drugs and environmental pollutants. Eur. J. Med. Chem. 2009, 44:2452-8. doi: 10.1016/j.ejmech.2009.01.009.

[144] Sim, M. R., McNeil, J. J. Monitoring chemical exposure using breast milk: A methodological review. Am. J. Epidemiol. 1992, 136:1-11. doi: 10.1093/oxfordjournals.aje.a116412. 
[145] Starkenmann, C. Analysis and chemistry of human odors. In: Buettner A, ed. Springer Handbook of Odor. Cham: Springer International Publishing; 2017. p. 121-2.

[146] Logan, Darren W., Brunet, Lisa J., Webb, William R., Cutforth, T., Ngai, J., Stowers, L. Learned recognition of maternal signature odors mediates the first suckling episode in mice. Curr. Biol. 2012, 22:1998-2007. doi: 10.1016/j.cub.2012.08.041.

[147] Edmond, K. M., Zandoh, C., Quigley, M. A., Amenga-Etego, S., Owusu-Agyei, S., Kirkwood, B. R. Delayed breastfeeding initiation increases risk of neonatal mortality. Pediatrics. 2006, 117:e380-e6. doi: $10.1542 /$ peds.2005-1496.

[148] Schaal, B. From amnion to colostrum to milk: odor bridging in early developmental transitions. In: Hopkins B, Johnson SP, eds. Prenatal development of postnatal functions. London: Praeger; 2005. p. 51-102.

[149] Schaal, B. How amniotic fluid shapes early odor-guided responses to colostrum and milk (and more). In: Guichard E, Salles C, Voilley A, eds. Flavor: From food to behaviour, wellbeing and health. Amsterdam: Elsevier; 2016. p. 23-53. 
Human milk odour affects mother-infant-interaction during breastfeeding.

Human neonates detect and respond to human milk odour by physiological and behavioural means.

Many odour-active molecules have been identified in human milk.

Issues that deserve attention in future research are highlighted, especially those concerning the communicative function of human milk odour. 